IFN Working Paper No. 817, 2010

\title{
Buying to Sell: A Theory of Buyouts
}

Pehr-Johan Norbäck, Lars Persson and Joacim Tåg 


\title{
Buying to Sell: A Theory of Buyouts*
}

\author{
Pehr-Johan Norbäck \\ Research Institute of Industrial Economics (IFN) \\ Lars Persson \\ Research Institute of Industrial Economics (IFN) and CEPR \\ Joacim Tåg \\ Research Institute of Industrial Economics (IFN)
}

August 23, 2010

\begin{abstract}
Private equity firms are an important part of the industrial restructuring process. We argue that the key is temporary ownership. Buying to sell induces aggressive restructuring since the equilibrium trade sale price increases both because the profits of the acquiring incumbent increase and the profits of non-acquiring incumbents decrease. Therefore, private equity backed firms are more leveraged and have managers with more ownership as compared to incumbents. By being outsiders, private equity firms specialize in restructuring to outbid incumbents with incentives to preemptively acquire targets. Welfare effects of buyouts are ambiguous, but consumers gain from a buyout.

Keywords: Buyouts, Buying to sell, LBO, M\&A, Private equity, Takeovers, Temporary ownership

JEL Codes: G24, G32, G34, L1, L2

\footnotetext{
*Financial support from the Marianne and Marcus Wallenberg Foundation and the Jan Wallander and Tom Hedelius Foundation is gratefully acknowledged. This paper was written within the Gustaf Douglas Research Program on Entrepreneurship. We thank Kevin Amess, Ulf Axelsson, Florian Ederer, Ioannis Floros, Richard Gilbert, Denis Gromb, Björn Hansson, Michael Katz, Evgeny Lyandres, Ludovic Phalippou, Gordon Phillips, Ramana Sonti, and seminar participants at the Institute for Financial Research, the Swedish Foundation for Small Business Research, the International Industrial Organization Conference 2009, the 11th Annual SNEE European Integration Conference, the CAF Summer Research Conference (Indian School of Business, Hyderabad), 24th Annual Congress of the European Economic Association, The IFN Stockholm Conference (Vaxholm, 2009 and 2010), and The Research Institute of Industrial Economics (IFN) for excellent comments and suggestions. We also thank Aron Berg for research assistance.Contact adress for authors: Research Institute of Industrial Economics (IFN), Box 55665, SE-102 15 Stockholm, Sweden. E-mail: firstname.lastname@ifn.se.
} 


\section{Introduction}

Private equity firms are an important part of the industrial restructuring process that is taking place in all industries across the world. Davis et al. (2009) show that around 2\% of US nonfarm employees worked in a private equity backed firm in 2005 and that productivity on average grows by about two percentages points more at private equity backed firms than at comparable firms in the manufacturing industry during two years after the transaction. Bloom et. al (2008) present evidence that private equity backed firms excel in people and operations management practices; skills that are important when restructuring activities are undertaken.

This raises the question of why private equity firms are so active at restructuring. We argue that the key is that private equity funds are set up to acquire and resell assets. The median holding period of a company in a private equity fund is around six years, with a trade sale to an incumbent as the most common exit route (occurring in $38 \%$ of all cases according to Kaplan and Strömberg, 2009). We show that exits though trade sales gives incentives for aggressive restructuring since the equilibrium trade sale price increases both because the profits of the acquiring incumbent increase and the profits of non-acquiring incumbents decrease. Moreover, by being initial outsiders to the industry, private equity firms have incentives to specialize in restructuring to outbid incumbents with incentives to preemptively acquire targets.

To make our argument, we develop a model where several symmetric incumbents compete in an oligopoly. One firm, the target, has assets in need of restructuring, but cannot restructure itself as it lacks resources or knowledge. The target's assets are sold to one of the incumbents, or to one of several competing private equity firms through a first-price perfect information auction. Post acquisition, the new owner hires a manager to restructure the assets, giving her a linear compensation contract consisting of a fixed wage and a share of the product market profits. Restructuring raises the product market profits of the eventual acquirer of the assets, but reduces the product market profits for its rivals. If a buyout takes place, the private equity firm then exits its investment through a trade sale to one of the incumbents (again through a first-price perfect information auction). Finally, all incumbents compete in the product market; one of them is in possession of the restructured assets.

In this setting, the equilibrium trade sale price consists of an incumbent's product market profits from owning the assets in relation to the profits arising if a rival incumbent obtains them. Private equity firms buying to sell (maximizing a trade sale price) thus have incentives to overinvest in restructuring compared to incumbents that buy to keep (maximizing product market profits). The trade sale price responds more to restructuring, since it both increases the product market profits of the incumbent acquiring the restructured assets (a "carrot effect") and decreases the product market profits of its rivals (a "stick effect"). Buying to sell thus gives incentives to "overinvest" in restructuring, as private equity firms account for the effects of restructuring on rivals in the industry. Given that ownership in the firm and debt induces a manager to work harder at restructuring, "overinvestment" is consistent with the empirical 
findings that private equity backed firms are more productive (Amess 2002, 2003; Harris et al. 2005, Davis et al. 2009), have managers with more intense compensation contracts (Kaplan, 1989a; Leslie and Oyer, 2008), and are more leveraged (Axelson et al., 2009).

But stronger incentives to restructure the target do not mean that private equity firms can outbid incumbents in the initial acquisition auction. Incumbents have incentives to preemptively acquire the target to prevent a buyout and the subsequent sale of an intensively restructured and competitive target back to the industry. We identify several reasons for why private equity buyouts take place in equilibrium despite the incumbent's incentives to preemptively acquire the target.

First, by being outsiders in the industry they have incentives to build up unique restructuring skills. Since private equity firms do not have industry specific assets that the incumbents have-and since incumbents will outbid the private equity firms if they are equally efficient at restructuring-private equity firms will have stronger incentives than incumbents to invest in acquiring restructuring skills. If they succeed, they are able to outbid incumbents.

Second, private equity firms may have exogenous cost advantages arising from preferential tax treatment or from easier access to capital due to long term relationships with banks and institutional investors. Such advantages could allow them to outbid incumbents.

Third, non-acquiring incumbents gain more from a direct preemptive acquisition than the acquiring incumbent. Thus, a coordination failure can emerge between incumbents and a private equity firm can outbid the incumbents with a positive probability.

Our paper contributes to three strands of literature. By studying acquisition, restructuring, and resale of assets in an oligopoly, we introduce private equity firms to the literature on industrial organization. The literature on mergers and acquisition tends to treat owner asymmetries, and pre- and post-merger investments, in a cursory way. An exception is Gowrisankaran (1999), who uses numerical methods to study the evolution of an industry allowing for entry, exit and investments as well as mergers. A large set of papers (Salant et al. 1983; Perry and Porter, 1985; Deneckere and Davidson, 1985; Farrell and Shapiro, 1990; Gilbert and Newbery, 1992) clarify how mergers affect prices, profits and welfare, depending on the market structure in various static oligopoly models. Such papers are sometimes referred to as the exogenous merger literature since the firms that merge are exogenously chosen. They do not touch on the terms of the deal and leave aside the strategic concerns we focus on. Recently, a literature on endogenous mergers has emerged in which the central question is who merges with whom (Kamien and Zang, 1990; Horn and Persson, 2001; Fridolfsson and Stennek, 2005). We add to this trend by showing that the presence of private equity firms specializing in buying to sell affects the merger and restructuring pattern in an industry. We identify an important role of the private equity firms as challengers of existing oligopolies through aggressive restructuring of firms up for sale. The welfare effects of buyouts are ambiguous, but consumers always gain from a buyout as opposed to an acquisition as a private equity backed firm will be more restructured (and hence more productive) compared to a firm bought by an incumbent. 
Our paper also relates to the finance literature on private equity buyouts. This literature has proposed that private equity firms are specialists at solving managerial agency problems, mainly through closer monitoring, extensive use of debt and giving the manager ownership in the firm (Jensen, 1986; 1989). By concentrating ownership, they are assumed solve freerider problems related to dispersed ownership (Berle and Means, 1932; Jensen and Meckling, 1979) and therefore have stronger incentives to improve governance. Yet, this approach fails to explain why boards of public companies do not implement the same measures as private equity backed firms (higher leverage and a closer connection between pay and performance) to induce more restructuring effort. We argue that this divergence can partly come from private equity firms buying with the intent of selling, whereas incumbents buy with the intent of keeping. Indeed, if agency problems are present, high managerial ownership or high leverage is required for private equity firms to induce more intense restructuring compared to incumbents. The fundamental difference in incentives to raise managerial ownership or leverage comes, however, from buying to sell versus buying to keep. Further, as we work with strategic product market effects it brings our paper into the literature on the interaction between financial markets and product markets (Brander and Lewis 1986, 1988; Maksimovic, 1988; Bolton and Scharfstein, 1990; Williams, 1995; Phillips, 1995; Chevalier, 1995a,b; and Miao, 2005). We contribute by showing that buying to sell affects compensation contracts and financial structure, which in turn affects investment behavior and product market performance.

Finally, our paper is a contribution to the literature on endogenous ownership and efficiency dating back to Coase (1960). He argued that in a zero-transaction world, laissez-faire always leads to optimal outcomes irrespective of assignment of property rights. Departing from the zero transaction cost assumption, Gans (2005), Grossman and Hart (1986), Hart and Moore (1990), among others, show that ownership structure has implications for efficiency in an incomplete contract framework. Jeheil and Moldovanu (1999) show that the outcome of a resale market is not efficient in a framework with externalities when commitments to future actions are not possible. We contribute by examining the outcome allowing for investments in the assets up for resale, which enables us to show that even if the assets end up in the hands of the most efficient owner, the equilibrium investment in the assets is not the efficient one. Owners buying assets for resale have incentives to overinvest in relation to the eventual acquirer's first best because of externalities in the resale auction (in accordance with Jehiel et al. 1999; Jehiel and Moldovanu, 1999, 2000). Moreover, we show that different owners face difference incentives to specialize in taking care of the assets such that ownership need to vary over time to achieve dynamic efficiency. The overinvestment effect is present also in Katz and Shapiro (1996) and Norbäck and Persson (2009), but in their settings owners cannot endogenously decide whether to sell or keep the assets or to specialize in different skills.

We have structured the paper in the following way. In section 2 we present the model and show that private equity firms buying to sell have incentives to induce more restructuring compared to incumbents buying to keep. To achieve this they give managers more ownership 
in the firm (and take on more debt). In section 3, we then ask when buyouts will occur in equilibrium. We demonstrate that incumbents have incentives to preemptively outbid private equity firms to prevent intense restructuring of the assets. But buyouts still occur if private equity firms have successfully acquired superior restructuring skills, if private equity firms have an exogenous cost advantage, or if incumbents fail to coordinate bidding. We discuss robustness and extensions to the model in section 4 , and mention empirical implications in section 5. We end with concluding remarks in section 6.

\section{Buying to sell, compensation contracts, and restructuring}

We begin by presenting our four stage model and solving the last three stages to illustrate the main mechanism: buying to sell leads to more intense compensation contracts for managers and more intense restructuring efforts compared to buying to keep. The model is based on the following observed industry characteristics:

- The product market is oligopolistic. Many buyouts take place in either mature concentrated industries or growing industries in which targets possess strategic assets. For example, Kovenock and Phillips (1995) find evidence that low productive firms in concentrated markets are more likely to face a buyout.

- Assets are acquired and sold through competitive auctions. As Boone and Mulherin (2007) show, the U.S. takeover market was competitive during the 1990s; the majority of all acquisitions took place after multiple bids had been submitted.

- Private equity firms are committed to sell the firms they acquire through their funds, since the funds they set up have limited time horizons after which they must be closed and the capital returned to investors.

- Exit takes place through a trade sale. Kaplan and Strömberg (2009) report that conditional on having exited, $38 \%$ of all exits are trade sales and only $14 \%$ are IPOs. We focus on trade sales as they are most common and discuss IPOs in section 4.

- Post-acquisition, the new owner implements governance, financial and operational improvements to restructure the target (Jensen 1986,1989; Kaplan and Strömberg 2009). The new owners in our model decide on incentive contracts for the managers, and managers then decide on restructuring intensity. We also develop a version of the model in section 4 in which debt replaces managerial ownership as a way of inducing managerial effort.

Formally, consider an oligopoly industry served by a set $\mathcal{I}=\{1,2, . ., i, \ldots, n\}$ of symmetric incumbents, each possessing the basic assets necessary for production. The industry also 


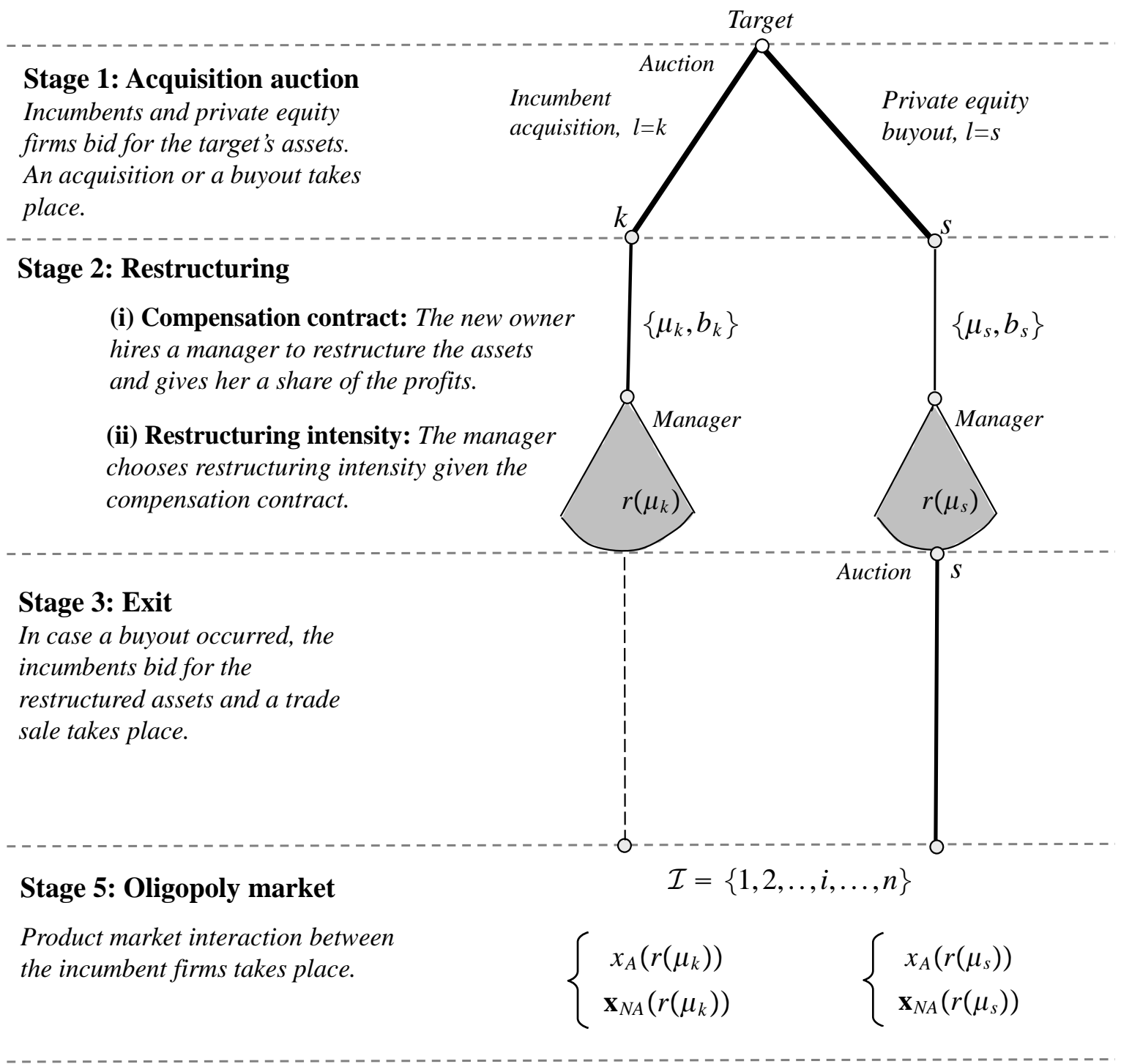

Figure 1: This figure illustrates and describes the four stage game we analyze: the initial acquisition auction, the restructuring and compensation stage, the exit auction, and oligopoly market interaction between incumbent firms.

contains a firm called the target. The target's assets are in need of restructuring, but the target cannot undertake the process by itself because of lack of cash or knowledge. The game is illustrated in Figure 1 and proceeds as follows.

In stage one, an acquisition of the target by incumbent $i$ or by the private equity firm $j \in$ $\mathcal{J}=\{1,2, . ., j, . ., m\}$ takes place at the acquisition price $S^{1}$ determined in a first-price perfect information auction with externalities. Externalities mean that the value of winning for a bidder is determined relative to what happens if the bidder loses the auction (Jehiel and Moldovanu (1999), Jehiel et al. (1999), Jehiel and Moldovanu (2000)). The new owner type $(l)$ is either an incumbent buying to keep $(l=k)$ or a private equity firm buying to sell $(l=s)$.

In stage two, the new owner hires a manager to restructure the assets. Because of moral hazard and risk aversion, the new owner must provide incentives for the manager to exert effort 
and offers the manager a share $\mu_{l}$ of the product market profits. The manager then determines the amount of restructuring, $r\left(\mu_{l}\right)$, to be undertaken.

In stage three, if the target was bought by a private equity firm, a trade sale of the target to one of the incumbents takes place. The trade sale price, $S^{3}$, is determined through a first price perfect information auction with externalities.

In stage four, incumbents compete in the product market by setting price or quantity $\left(x_{i}\right)$, given how much the assets were restructured $\left(r\left(\mu_{l}\right)\right)$ and who is in possession of the assets $(z \in I)$. Incentive problems are restricted to the restructuring stage, and do not appear in the product market interaction stage.

\subsection{Stage four: product market interaction}

Using backward induction, we start in stage four with product market competition between the $n$ incumbents. One of them owns the restructured target. Since product market competition takes place post-exit, private equity firms do not own assets in this stage and hence do not produce.

Each incumbent $i$ chooses an action $\in R^{+}$to maximize the direct product market profit $\Pi_{i}\left(x_{i}, \mathbf{x}_{-i}, r, z\right)$. The profit depends on its own actions $x_{i} ;$ its rivals' actions $\mathbf{x}_{-i}($ an $(N-1) \times 1$ vector); how much the target has been restructured $(r)$; and the identity of the incumbent in possession of the target $(z)$. We assume a unique Nash-Equilibrium in actions, $\mathbf{x}^{*}(r, z)$, exists and that it is defined from the first-order conditions

$$
\frac{\partial \prod_{i}}{\partial x_{i}}\left(x_{i}^{*}, \mathbf{x}_{-i}^{*} ; r, z\right)=0, \forall i .
$$

Using the ex-ante symmetry among incumbents, we can drop $z$ and distinguish between two firm types: the acquiring incumbent $(A)$ and the non-acquiring incumbents $(N A)$. Since the optimal action for the acquirer $\left(x_{A}^{*}\right)$ and actions for the non-acquirers $\left(x_{N A}^{*}\right)$ only depend on the level of restructuring $r$, we can define the reduced-form product market profits of the acquirer and a non-acquirer as direct functions of $r$ :

$$
\begin{aligned}
R_{A}(r) & \equiv \Pi_{A}(x_{A}^{*}(r), \underbrace{x_{N A}^{*}(r), \ldots, x_{N A}^{*}(r)}_{n-1}, r), \text { and } \\
R_{N A}(r) & \equiv \Pi_{N A}(x_{N A}^{*}(r), \underbrace{x_{N A}^{*}(r), \ldots, x_{N A}^{*}(r)}_{n-2}, x_{A}^{*}(r), r) .
\end{aligned}
$$

Restructuring increases the profits of the acquirer, but reduces the profits for non-acquiring incumbents as they must compete with a better rival.

Assumption $1 \frac{d R_{A}}{d r}>0$ and $\frac{d R_{N A}}{d r}<0$.

This assumption is compatible with several oligopoly models. One example is the linear Cournot model: 
Example 1 (The LC-model) The oligopoly interaction is Cournot competition with homogenous goods. The product market profit is $\Pi_{j}=\left(P_{j}-c_{j}\right) q_{j}$ where firms face inverse demand $P=a-Q$, where $a>0$ is a demand parameter and $Q=\Sigma_{j=1}^{N} q_{j}$ is aggregate output. In the LC-model, ownership of the invention reduces the marginal cost. Making a distinction between firm types, we have:

$$
c_{A}=c-r, \quad c_{N A}=c .
$$

In the LC model, equation (1) then takes the form $\frac{\partial \Pi_{h}}{\partial q_{h}}=P-c_{h}-\frac{q_{h}}{s}=0$ for $h=\{A, N A\}$, which can be solved for optimal quantities $\mathbf{q}^{*}=\left(q_{h}^{*}, q_{-h}^{*}\right)$, where $q_{h}^{*}$ is the output of a firm of type $h$ and $q_{-h}^{*}$ the output of its competitors. Noting that $\frac{\partial \Pi_{h}}{\partial q_{h}}=0$ implies $P-c_{h}=\frac{q_{h}^{*}}{s}$, reduced-form profits are $R_{h}=\frac{1}{s}\left[q_{h}^{*}\right]^{2}$. The equilibrium outputs for the two types of firms are $q_{A}^{*}=s \frac{a-c+N r}{N+1}$, and $q_{N A}^{*}=s \frac{a-c-r}{N+1}$.

In the LC-model, it is easy to see that $\frac{d R_{A}}{d r}>0$ and $\frac{d R_{N A}}{d r}<0$. But Assumption 1 is also compatible with many other oligopoly models with other competitive modes, cost and demand structures such as Bertrand models with differentiated products and multi-plant models as long as restructuring either affects the variable production cost or the quality of the product sold by the incumbent in possession of the restructured assets. For example Assumption 1 will be fulfilled for many parameters values in the following differentiated product multi-plant model (DMP-model):

Example 2 (The DMP-model) Let each firm initially own and produce one product. Let the inverse demand of a product be $P_{j}=a-q_{j}-\gamma q_{-j}$, in which $\gamma \in[0,1]$ is the degree of product substitutability $\left(\gamma=0\right.$ implies a monopoly and $\gamma=1$ implies homogenous goods), $q_{j}$ is the output of product $j$ and $q_{-j}$ is the output of the other products. The product market profit for a firm with product $j$ is $\Pi_{j}=\left(P_{j}-c_{j}\right) q_{j}$. Dividing up in firm types, assume that marginal costs are:

$$
c_{A}=c-\bar{k}, \quad c_{N}=c-\bar{k}, \quad c_{T}=c-r .
$$

where $c_{T}$ is the marginal cost of the target firm and $\bar{k}$ represents firm-specific assets. Note that the acquirer will own two products (its own product and the target firm's product). The Nash-Cournot equilibrium $\mathbf{q}^{*}=\left(q_{h}^{*}, q_{-h}^{*}\right)$ is then determined from the first-order conditions $\frac{\partial\left(\Pi_{A}+\Pi_{T}\right)}{\partial q_{T}}=0$ and $\frac{\partial\left(\Pi_{A}+\Pi_{T}\right)}{\partial q_{A}}=0$ for the acquirer, and $\frac{\partial \Pi_{N}}{\partial q_{N}}=0$ for a non-acquirer. We can then define $R_{A}=\left[P_{A}\left(\mathbf{q}^{*}\right)-c_{A}\right] q_{A}^{*}+\left[P_{T}\left(\mathbf{q}^{*}\right)-c_{T}\right] q_{T}^{*}$ as the associated reduced-form profit function for the acquirer and $R_{N}=\left[P_{N}\left(\mathbf{q}^{*}\right)-c_{N}\right] q_{N}^{*}$ as the reduced profit function for a nonacquirer. The DMP-model can also be solved for Bertrand competition. The inverse demand function in $P_{j}=a-q_{j}-\gamma q_{-j}$ is inverted into direct demand, $q_{j}(\mathbf{p}, \gamma)$, with $\mathbf{p}=\left(p_{j}, p_{-j}\right)$. Dividing into firm types, the direct profit is $\Pi_{h}=\left(p_{h}-c_{h}\right) q_{h}(\mathbf{p})$. Let $\mathbf{p}^{*}=\left(p_{h}^{*}, p_{-h}^{*}\right)$ be the Nash-Bertrand equilibrium from the first-order conditions $\frac{\partial\left(\Pi_{A}+\Pi_{T}\right)}{\partial p_{T}}=0$ and $\frac{\partial\left(\Pi_{A}+\Pi_{T}\right)}{\partial p_{A}}=$ 0 for the acquirer, and $\frac{\partial \Pi_{N}}{\partial p_{N}}=0$ for a non-acquirer. From these conditions we can define 
$\left.R_{A}=\left[p_{A}^{*}-c_{A}\right] q_{A}\left(\mathbf{p}^{*}\right)+\left[p_{T}^{*}-c_{T}\right)\right] q_{T}\left(\mathbf{p}^{*}\right)$ and $R_{N}=\left[p_{N}^{*}-c_{N}\right] q_{N}\left(\mathbf{p}^{*}\right)$ as the associated reduced-form profit functions.

It can be shown that in the DMP-model, regardless if there is Bertrand or Cournot competition, Assumption 1 holds as long target firm has sufficiently low variable costs relative to incumbents before restructuring take place. From (5), this implies that $\bar{k}$ cannot be too large relative to $r$. Intuitively, if an incumbent has a very efficient production of its own product an increase in restructuring $r$ of the target firm's product will cannibalize on profitable sales in its original plant, and thereby reduce aggregate profits (implying that $\frac{d R_{A}}{d r}<0$ ). However, Assumption 1 holding for all parameter values is only a sufficient condition for our analysis. It could be that Assumption 1 holds for some values of $r$ which is all that is needed for our analysis.

\subsection{Stage three: the exit auction}

If a buyout takes place in stage one, the private equity firm exits its investment through a first price perfect information auction with externalities. The $n$ incumbents simultaneously post bids, which are accepted or rejected by the private equity firm. Each incumbent announces a bid, $b_{i}$, with $b=\left(b_{1}, \ldots, b_{i}, \ldots b_{n}\right) \in R^{n}$ being the vector of these bids. Following the announcement of $b$, the restructured target is sold to the incumbent with the highest bid. If more than one firm makes an offer of the highest value, each such incumbent obtains the target with equal probability.

The exit auction is solved for Nash equilibria in undominated pure strategies. There is a smallest amount, $\varepsilon$, chosen such that all inequalities are preserved if $\varepsilon$ is added or subtracted. An incumbent's maximum willingness to pay for the target is

$$
\omega_{k k}=R_{A}(r)-R_{N A}(r) .
$$

The first term shows the profit for the incumbent if it obtains the target. The second term shows the profit of the same incumbent if it does not obtain the target and is forced to compete with a rival that obtained the target. Denote the trade sale price in stage three by $S^{3}(r)$. Lemma 1 follows.

Lemma 1 The equilibrium trade sale price is $S^{3}(r)=R_{A}(r)-R_{N A}(r)$.

Proof. See the appendix.

This lemma follows since the incumbents are ex-ante symmetric and hence, their valuations are symmetric and they will all post the same bid equal to their maximum valuation of obtaining the restructured assets from the private equity firm. 


\subsection{Stage two: managerial ownership and restructuring}

In stage two, the new owner hires a manager to restructure the assets. Because of moral hazard, the owners give the manager a share of product market profits in addition to a fixed wage. Uncertain restructuring costs in combination with CARA preferences for the manager make it costly for the owners to give the manager a share of the profits. This cost must be balanced with the incentive effects of higher managerial ownership.

The restructuring costs for the firm, net of managerial compensation, are uncertain and given by $F-\varepsilon$, with $\varepsilon \sim N\left(0, \sigma^{2}\right)$. The personal effort cost of restructuring for the manager is $C(r)$, with $C^{\prime}(r)>0$ and $C^{\prime \prime}(r)>0$ : the more restructuring, the harder the decisions the manager must make. The manager is risk averse and has CARA preferences,

$$
u(w, r)=-e^{-\eta[w(b, \mu, r)-C(r)]},
$$

in which $\eta$ measures the degree of risk aversion.

The restructuring effort undertaken by the manager is observed but not verifiable and cannot be contracted on. The manager is therefore offered a linear contract $\{b, \mu\}$ consisting of a fixed wage $b$ and a share $\mu \in[0,1]$ of the product market profits net of restructuring costs:

$$
w=b+\mu\left[R_{A}(r)-F+\varepsilon\right]
$$

In what follows, we first solve for the restructuring decision of the manager given the compensation contract, and then turn to the optimal contract to offer the manager.

\subsubsection{Restructuring effort by the manager}

Consider the manager's decision on how much restructuring $(r)$ to undertake given contract $\{b, \mu\}$. The manager exerts an effort to restructure the target by maximizing expected utility:

$$
\mathrm{E}[u(w, r)]=-e^{-\eta\left[b+\mu\left[R_{A}(r)-F\right]-C(r)\right]} \mathrm{E}\left[e^{-\eta \mu \varepsilon}\right] .
$$

This expression follows from equation (7) and (8). We can separate out the stochastic term $\varepsilon$, and since $\varepsilon \sim N\left(0, \sigma^{2}\right)$ it follows that $\mathrm{E}\left[e^{-\eta \mu \varepsilon}\right]=e^{-\eta^{2} \mu^{2} \frac{\sigma^{2}}{2}}$. Defining $\Omega(\mu)=\eta \mu^{2} \frac{\sigma^{2}}{2}$ as the risk premium given to the manager, it follows that the optimal restructuring is defined as

$$
r^{*}=\arg \max _{r} \mathrm{E}[u(w, r)]=\arg \max _{r}\left[b+\mu\left[R_{A}(r)-F\right]-C(r)-\Omega(\mu)\right] .
$$

The associated first-order condition is

$$
\mu \frac{d R_{A}}{d r}=C^{\prime}\left(r^{*}(\mu)\right)
$$


with $\mu \frac{d R_{A}}{d r}$ being the marginal increase in the manager's compensation and $C^{\prime}$ the marginal increase in her effort cost.

From equation (11), the optimal restructuring undertaken by the manager $r^{*}(\mu)$ increases in $\mu$ since

$$
\frac{d r^{*}}{d \mu}=-\frac{R_{A}^{\prime}}{\mu R_{A}^{\prime \prime}-C^{\prime \prime}}>0
$$

Here we have used the short notation $R_{A}^{\prime}=d R_{A} / d r$ and $R_{A}^{\prime \prime}=d^{2} R_{A} / d r^{2}$, and assumed that the second-order condition $\mu R_{A}^{\prime \prime}-C^{\prime \prime}<0$ is satisfied. We depict optimal restructuring effort by the manager in Figure 2(i) as the upward-sloping locus $r^{*}(\mu)$.

From equation (11), it is also convenient define reduced-form expressions for the profit functions of the incumbents $R_{h}(\mu) \equiv R_{h}\left(r^{*}(\mu)\right)$ for $h=\{A, N A\}$; the compensation contract to the manager $w(b, \mu) \equiv b+\mu\left[R_{A}\left(r^{*}(\mu)\right)-F+\varepsilon\right]$; and for the effort cost of the manager, $C(\mu) \equiv C\left(r^{*}(\mu)\right)$.

\subsubsection{The contract offered by an incumbent}

Suppose now that a buy-to-keep incumbent has obtained the target in stage one. The incumbent will maximize expected profits $E\left[R_{A}\left(\mu_{k}\right)-F+\varepsilon-w\left(b_{k}, \mu_{k}\right)\right]$ by choosing the contract $\left\{b_{k}, \mu_{k}\right\}$ optimally. Assuming perfect competition between managers, the optimal contract must fulfill the participation constraint $w\left(b_{k}, \mu_{k}\right)-C\left(\mu_{k}\right)-\Omega\left(\mu_{k}\right)=\bar{w}$, with $\bar{w}$ being the outside option for the managers. Solving $w\left(b_{k}, \mu_{k}\right)=\bar{w}+C\left(\mu_{k}\right)+\Omega\left(\mu_{k}\right)$ from the participation constraint, using $\mathrm{E}[\varepsilon]=0$, the expected profit for the incumbent can be written as

$$
\mathrm{E}\left[R_{A}\left(\mu_{k}\right)-F+\varepsilon-w\left(b_{k}, \mu_{k}\right)\right]=R_{A}\left(\mu_{k}\right)-\Gamma\left(\mu_{k}\right)
$$

in which $\Gamma\left(\mu_{k}\right)=F+\bar{w}+C\left(\mu_{k}\right)+\Omega\left(\mu_{k}\right)$ is the total costs of restructuring (the sum of the expected fixed restructuring cost and the compensation paid to the manager).

It follows from equation (13) that the optimal share to give to the manager is $\mu_{k}^{*}=\arg \max _{\mu_{k}}\left[R_{A}\left(\mu_{k}\right)-\right.$ $\left.\Gamma\left(\mu_{k}\right)\right]$ with associated first-order condition

$$
\frac{d R_{A}}{d r} \frac{d r^{*}}{d \mu}=\Gamma^{\prime}\left(\mu_{k}^{*}\right)
$$

The optimal share $\mu_{k}^{*}$ is shown point $K$ in Figure 2(ii). The marginal revenue from giving a higher share to the manager is $\frac{d R_{A}}{d r} \frac{d r^{*}}{d \mu}$, consisting of the marginal increase in restructuring from an increased share $\left(\frac{d r^{*}}{d \mu}>0\right)$ and the marginal effect of restructuring on profits $\left(\frac{d R_{A}}{d r}>0\right)$. The corresponding marginal cost of giving the manager a larger share is $\Gamma^{\prime}=\frac{d \Gamma}{d \mu}=\frac{d C}{d r} \frac{d r^{*}}{d \mu}+\Omega^{\prime}(\mu)$, consisting of the marginal effect of a share increase on the personal effort cost through increased restructuring $\left(\frac{d C}{d r} \frac{d r^{*}}{d \mu}>0\right)$, and the marginal effect on the risk premium $\left(\Omega^{\prime}(\mu)>0\right)$. In other words, the benefit of giving the manager more ownership in the firm is an increase in profits 


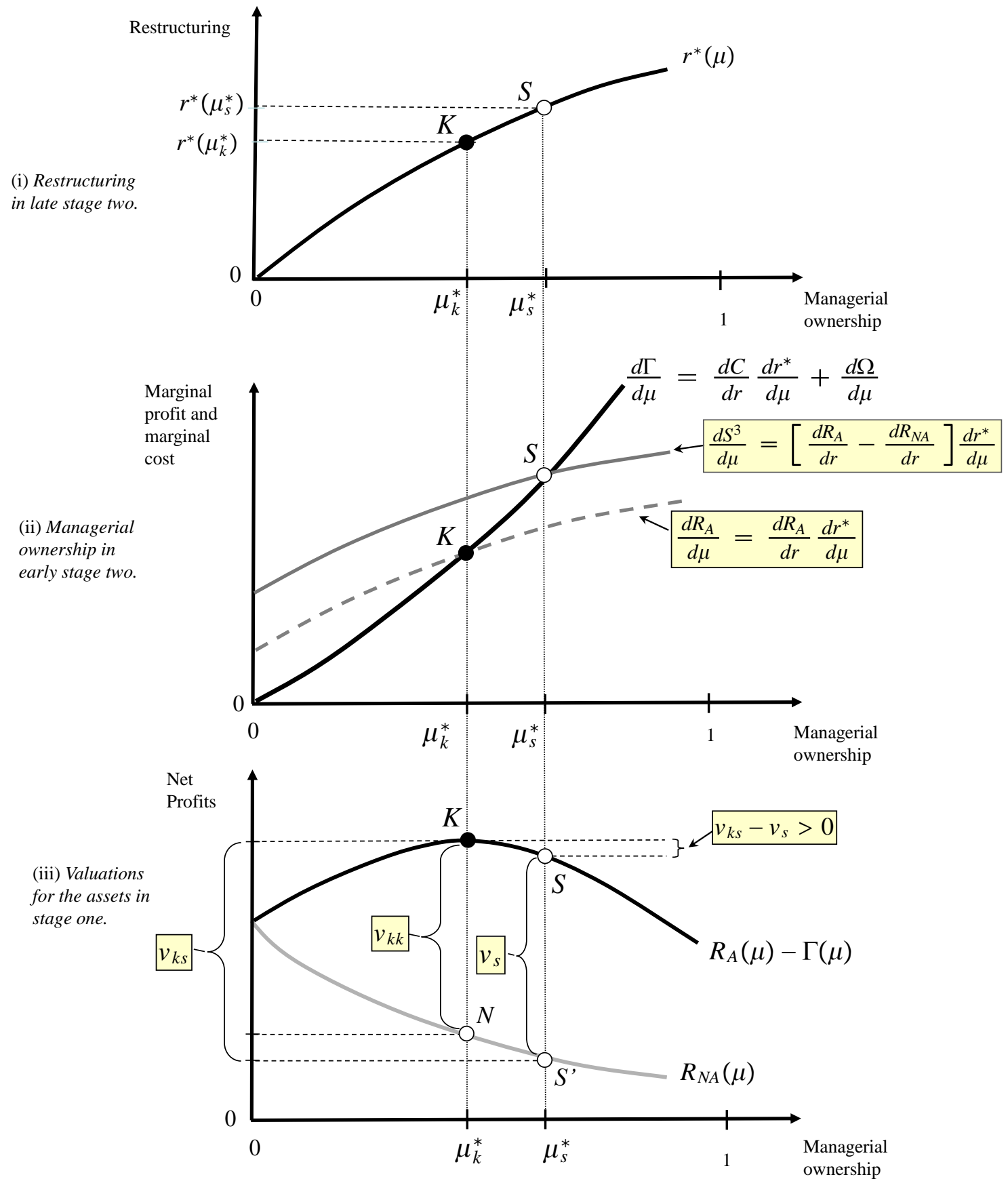

Figure 2: Illustrating the solution to stage one and two. Part (i) depicts the optimal restructuring effort by the manager as the upward-sloping locus $r^{*}(\mu)$. Part (ii) shows how buying to sell gives a higher marginal revenue curve compared to buying to keep and leads to a stronger incentive contract for the manager. Part (iii) illustrates how the maximum valuations in stage one are determined. Incumbents have incentives to outbid private equity firms. 
from increased restructuring effort, but the cost is that the manager now demands a higher wage both because exerting effort is costly and because the manager must take on more restructuring risk.

The optimal share of ownership to give the manager balances these effects. An incumbent buying to keep will thus offer the manager a contract consisting of the share $\mu_{k}^{*}$ given from equation (14) combined with the fixed wage $b_{k}^{*}$ given from the participation constraint $w\left(b_{k}^{*}, \mu_{k}^{*}\right)-C\left(r^{*}\left(\mu_{k}^{*}\right)\right)-\Omega\left(\mu_{k}^{*}\right)=\bar{w}$.

\subsubsection{The contract offered by a private equity firm}

Suppose instead that a private equity firm obtained the target in stage one. A private equity firm will maximize the expected trade sale price net of total restructuring costs. Recall that from Lemma 1, the trade sale price is $S^{3}\left(\mu_{s}\right)=R_{A}\left(\mu_{s}\right)-R_{N A}\left(\mu_{s}\right)$. Solving the manager's compensation $w\left(b, \mu_{s}\right)=\bar{w}+C\left(\mu_{s}\right)+\Omega\left(\mu_{s}\right)$ from her participation constraint and noting that $\mathrm{E}[\varepsilon]=0$, it follows that the expected profit for a private equity firm can be written as

$$
\mathrm{E}\left[S^{3}\left(\mu_{s}\right)-F+\varepsilon-w\left(b, \mu_{s}\right)\right]=R_{A}\left(\mu_{s}\right)-R_{N A}\left(\mu_{s}\right)-\Gamma\left(\mu_{s}\right),
$$

in which total restructuring costs are $\Gamma\left(\mu_{s}\right)=F+\bar{w}+C\left(\mu_{s}\right)+\Omega\left(\mu_{s}\right)$.

From equation (15), it follows that the optimal share to give to the manager is $\mu_{s}^{*}=$ $\arg \max _{\mu}\left[R_{A}(\mu)-R_{N A}(\mu)-\Gamma(\mu)\right]$ with associated first-order condition

$$
\left[\frac{d R_{A}}{d r}-\frac{d R_{N A}}{d r}\right] \frac{d r^{*}}{d \mu}=\Gamma^{\prime}\left(\mu_{s}^{*}\right)
$$

The optimal equity share $\mu_{s}^{*}$ is given from point $S$ in Figure 2(ii). The marginal revenue of giving a higher share to the manager is $\left[\frac{d R_{A}}{d r}-\frac{d R_{N A}}{d r}\right] \frac{d r^{*}}{d \mu}$, reflecting the effect of a higher share on restructuring $\left(\frac{d r^{*}}{d \mu}\right)$, and the effect of higher restructuring on the trade sale price $\left(\frac{d S^{3}}{d r}=\right.$ $\left.\frac{d R_{A}}{d r}-\frac{d R_{N A}}{d r}\right)$. As for the incumbent, the marginal cost in terms of higher compensation is $\Gamma^{\prime}=\frac{d \Gamma}{d \mu}=\frac{d C}{d r} \frac{d r^{*}}{d \mu}+\Omega^{\prime}>0$, reflecting both the effect from increased personal effort costs for the manager and an increase in the risk premium. In other words, the benefit of giving the manager more ownership in the firm backed by a private equity firm is an increase in the trade sale price from increased restructuring effort. The trade sale price rises in restructuring both because it increases the profits of the acquiring incumbent and because it decreases profits for non-acquiring incumbents. And again, the cost is that the manager now demands a higher wage because exerting effort is costly and because the manager must take on more restructuring risk.

Thus, in a private equity backed firm, the manager will be given a contract consisting of the share $\mu_{s}^{*}$ given from equation (16) combined with the fixed wage $b_{s}^{*}$ from the participation constraint $w\left(b_{s}^{*}, \mu_{s}^{*}\right)-C\left(\mu_{s}^{*}\right)-\Omega\left(\mu_{s}^{*}\right)=\bar{w}$. 


\subsection{Why buying to sell leads to powerful incentive contracts and intense restructuring}

Let us now compare the incentive contract given to the manager by a private equity firm with a contract given to the manager by an incumbent.

Proposition 1 Managers in private equity backed firms have stronger incentive contracts than managers in incumbent firms $\left(\mu_{s}^{*}>\mu_{k}^{*}\right)$ and subsequently undertake more restructuring $\left(r^{*}\left(\mu_{s}^{*}\right)>\right.$ $\left.r^{*}\left(\mu_{k}^{*}\right)\right)$.

The proof of Proposition 1 follows directly from the first order conditions in equations (14) and (16). To see this, have a quick look at Figure 2(ii). The marginal cost of increasing the manager's share, $\Gamma^{\prime}$, reflects higher wage demands from higher effort cost of restructuring and for taking on higher risk. From equation (8), an incumbent buying to keep and a private equity firm buying to sell share this same marginal cost. However, the marginal revenue of increasing the share $\mu$ is not the same: an incumbent buying to keep accounts for how restructuring increases the product market profits of the firm $\left(\frac{d R_{A}}{d r} \frac{d r^{*}}{d \mu}>0\right)$, while a private equity firm buying to sell accounts for how restructuring increases the trade sale price. The trade sale price increases both because product market profits of an acquiring incumbent increases $\left(\frac{d R_{A}}{d r} \frac{d r^{*}}{d \mu}>0\right)$, and because the product market profits of non-acquiring incumbents decrease $\left(\frac{d R_{N A}}{d r} \frac{d r^{*}}{d \mu}<0\right)$.

Comparing equations (14) and (16), the effect on non-acquiring incumbents causes a private equity firm buying to sell to give the manager a stronger incentive contract $\left(\mu_{s}^{*}>\mu_{k}^{*}\right)$ than an incumbent buying to keep. In Figure 2(ii) this shown by the location of point $S$ to the right of point $K$. Since managers in private equity backed firms have stronger incentive contracts, it follows directly from (12) that they do more restructuring compared to managers working for incumbents $\left(r^{*}\left(\mu_{s}^{*}\right)>r^{*}\left(\mu_{k}^{*}\right)\right.$, illustrated in Figure 2(i)).

\section{The equilibrium emergence of private equity firms}

The next step is to move back to stage one of the model and study the initial acquisition auction. The bidders are private equity firms buying to sell and incumbents buying to keep. The question we ask is when private equity firms buying to sell are able to outbid incumbents buying to keep. In oligopolistic markets, letting a private equity firm acquire the assets means that incumbents will either end up with a rival with more competitive assets, or bid intensively against other incumbents for the restructured assets in a later stage. As such, incumbents have incentives to preemptively outbid private equity firms in order to prevent overinvestment (from their perspective) in restructuring the assets. We identify three reasons why private equity buyouts take place in equilibrium: a coordination failure can emerge between incumbents, private equity firms can have exogenous cost advantages compared to incumbents, and private equity firms have incentives to invest in acquiring specialized restructuring skills. 


\subsection{Stage one: the acquisition auction}

As in stage three, the acquisition auction in stage one is a first price perfect information auction with externalities. Again, we solve for Nash equilibria in undominated pure strategies. The $n$ incumbents and the $m$ private equity firms simultaneously post bids, which are accepted or rejected by the target. Each incumbent and private equity firm announces a bid, $b_{i}$, with $b=\left(b_{1}, \ldots, b_{i}, \ldots b_{n+m}\right) \in R^{n+m}$ is the vector of these bids. Following the announcement of $b$, the target is sold to the incumbent or the private equity firm with the highest bid. If more than one firm makes an offer of the highest value, each such bidder obtains the target with equal probability.

Since the auction has externalities, the maximum valuations are determined as profits from winning the auction in relation to profits from losing it. Remembering that $\mathrm{E}[\varepsilon]=0$, we work without the expectations operator and define the valuations $v_{s}, v_{k k}$ and $v_{k s}$ as follows.

- $v_{s}$ is the valuation of obtaining the target for a private equity firm buying to sell. To derive $v_{s}$, evaluate the expected profit for a private equity firm in equation (15) at the level of restructuring induced by the optimal share $\mu_{s}^{*}$ to obtain

$$
v_{s}=\underbrace{R_{A}\left(\mu_{s}^{*}\right)-R_{N A}\left(\mu_{s}^{*}\right)}_{\text {Trade sale price } S^{3}\left(\mu_{s}^{*}\right)}-\Gamma\left(\mu_{s}^{*}\right) .
$$

- $v_{k k}$ is an incumbent's valuation of obtaining the target if another incumbent would otherwise have obtained it. Evaluating the expected profit of an incumbent in equation (13) and the reduced-form profit for an non-acquiring incumbent at the optimal share $\mu_{k}^{*}$, we obtain

$$
v_{k k}=\underbrace{R_{A}\left(\mu_{k}^{*}\right)-\Gamma\left(\mu_{k}^{*}\right)}_{\text {Acquire and restructure. }}-\underbrace{R_{N A}\left(\mu_{k}^{*}\right)}_{\text {Let rival acquire. }} .
$$

- $v_{k s}$ is an incumbent's valuation of obtaining the target if a private equity firm would otherwise have obtained it, restructured it, and sold it back to the industry. Thus, evaluating the expected profit of an incumbent in equation (13) at the optimal share $\mu_{k}^{*}$ and reduced-form profit for an non-acquiring incumbent at the optimal equity share $\mu_{s}^{*}$, we obtain

$$
v_{k s}=\underbrace{R_{A}\left(\mu_{k}^{*}\right)-\Gamma\left(\mu_{k}^{*}\right)}_{\text {Acquire and restructure. }}-\underbrace{R_{N A}\left(\mu_{s}^{*}\right)}_{\text {Let buyout occur. }}
$$

These valuations can be ranked in six ways and the auction solved by considering each ranking in turn.

Lemma 2 The equilibrium ownership of the target and the acquisition price $S^{1}$ in stage one is given in Table I. 


\begin{tabular}{clcc} 
Inequality & Definition & Winning type & Acquisition price, $S^{1}$ \\
\hline$I 1$ & $v_{k k}>v_{k s}>v_{s}$ & $k$ & $v_{k k}$ \\
$I 2$ & $v_{k k}>v_{s}>v_{k s}$ & $k$ or $s$ & $v_{k k}, v_{s}$ \\
$I 3$ & $v_{k s}>v_{k k}>v_{s}$ & $k$ & $v_{k k}$ \\
$I 4$ & $v_{k s}>v_{s}>v_{k k}$ & $k$ & $v_{s}$ \\
$I 5$ & $v_{s}>v_{k k}>v_{k s}$ & $s$ & $v_{s}$ \\
$I 6$ & $v_{s}>v_{k s}>v_{k k}$ & $s$ & $v_{s}$ \\
\hline
\end{tabular}

Table I: This table describes the equilibrium ownership type ( $k$ or $s$ ) and the acquisition price $S^{1}$ for each possible ranking of the valuations $v$.

Proof. See the Appendix.

Lemma 2 gives the equilibrium ownership structure for any ranking of the valuations. Given equations (17), (18) and (19), we obtain the following proposition.

Proposition 2 Private equity firms cannot outbid incumbents in the initial acquisition auction. The target is acquired by an incumbent at the acquisition price $S^{1}=v_{s}$.

The reasoning behind Proposition 2 is the following. The valuations can be uniquely ranked as $v_{k s}>v_{s}>v_{k k}$, making inequality $I 4$ in Lemma 2 the relevant one. Since multiple private equity firms bid for the target, the acquisition price $S^{1}$ is at least $v_{s}$. A private equity firm must also have a higher maximum valuation than an incumbent preempting a rival acquisition: $v_{s}>v_{k k}$. This follows directly since when setting the compensation contract, a private equity firm sets the share $\mu_{s}$ to maximize exactly $v_{s}$ :

$$
\mu_{s}^{*}=\arg \max _{\mu}\left[S^{3}(\mu)-\Gamma(\mu)\right]=\arg \max _{\mu}\left[R_{A}(\mu)-R_{N A}(\mu)-\Gamma(\mu)\right] .
$$

Hence, it must be that $v_{s}=R_{A}\left(\mu_{s}^{*}\right)-R_{N A}\left(\mu_{s}^{*}\right)-\Gamma\left(\mu_{s}^{*}\right)>v_{k k}=R_{A}\left(\mu_{k}^{*}\right)-\Gamma\left(\mu_{k}^{*}\right)-R_{N A}\left(\mu_{k}^{*}\right)$ since $\mu_{s}^{*}>\mu_{k}^{*}$ and $\mu_{s}^{*}$ maximizes $v_{s}$. This is illustrated in Figure 2(iii), in which $v_{s}>v_{k k}$. Figure 2(iii) also reveals that an incumbent has an incentive to preempt private equity firms: $v_{k s}>v_{s}$. This is true since

$$
v_{k s}-v_{s}=R_{A}\left(\mu_{k}^{*}\right)-\Gamma\left(\mu_{k}^{*}\right)-\left[R_{A}\left(\mu_{s}^{*}\right)-\Gamma\left(\mu_{s}^{*}\right)\right]
$$

is always larger than zero since $\mu_{k}^{*}=\arg \max _{\mu}\left[R_{A}(\mu)-\Gamma(\mu)\right]$ and $\mu_{s}^{*}>\mu_{k}^{*}$.

Intuitively, since a private equity firm buying to sell induces more restructuring $\left(r_{s}^{*}>r_{k}^{*}\right)$, incumbents realize that if they let a private equity firm acquire the assets, they will face a more competitive firm in the industry once restructuring is done and the target is sold back to the industry. Even if they end up acquiring the assets in the exit auction, they will be no better off (they net $R_{N A}\left(\mu_{s}^{*}\right)$ in both cases). Thus, they realize that the value of preventing a buyout $\left(v_{k s}\right)$ is higher than the value of preventing a rival incumbent from obtaining the assets $\left(v_{k k}\right)$ and thus one of them outbids the private equity firms. 


\subsection{Buyouts in equilibrium}

Let us now discuss three reasons for why private equity buyouts take place in equilibrium: private equity firms have incentives to invest in acquiring specialized restructuring skills, private equity firms can have exogenous cost advantages compared to incumbents, and a coordination failure can emerge between incumbents.

\subsubsection{Specialization in restructuring}

Private equity firms are fundamentally outsiders in the industry: they do not own any assets in the market prior to bidding for the target's assets. Since private equity firms do not have industry specific assets that the incumbents have-and since incumbents will outbid the private equity firms if they are equally efficient at restructuring-private equity firms will have stronger incentives than incumbents to invest in acquiring restructuring skills. If they succeed, they are able to outbid incumbents. More specifically, in this section, we show that if private equity firms and incumbents can choose to invest in acquiring specialized restructuring skills prior to bidding for the target's assets in stage one, there exists an asymmetric equilibrium in which private equity firms specialize at restructuring and outbid incumbents with a positive probability in the acquisition auction in stage one.

To show this we add a stage zero to the game in which agents can invest in restructuring skills. To simplify, we assume that there are five agents in the market: the target $(t)$, two potential incumbent acquirers $\left(k_{1}\right.$ and $\left.k_{2}\right)$ and two private equity firms $\left(s_{1}\right.$ and $\left.s_{2}\right)$. The two incumbent firms and the two private equity firms choose simultaneously in stage zero whether to retain the fixed restructuring cost $F$, or to invest in acquiring specialized restructuring skills at cost $\Psi$. Investing in acquiring restructuring skills sets the fixed restructuring costs to zero with probability $1 / 2$ and to $F$ with probability $1 / 2$. The expected restructuring costs are thus $\tilde{F}=\frac{1}{2} F$. The draws of $\tilde{F}$ become common knowledge in the end of period zero.

We will now show that an asymmetric Nash-equilibrium exists in which private equity firms (without prior assets in the market) invest in acquiring specialized restructuring skills while incumbents choose not to acquire these skills. Buyouts then occur in equilibrium if at least one of the private equity firms gets a good draw and thus lowers the restructuring cost from $F$ to zero.

Consider first the private equity firms. Formally, let $\left(F_{s_{1}}, F_{s_{2}}, F_{k_{1}}, F_{k_{2}}\right)=(\tilde{F}, \tilde{F}, F, F)$ be the equilibrium candidate. First, consider deviation by a private equity firm. Let $\Pi_{s}(\tilde{F} \mid \tilde{F}, F, F)$ be the expected profit for a private equity firm of investing in restructuring when the other private equity firm also invests, but no incumbent invests. Since incumbents have an incentive to preempt private equity firms at symmetric restructuring costs, $v_{k s}>v_{s}$, the expected profit from not investing is zero $\Pi_{s}(F \mid \tilde{F}, F, F)=0$. Thus, a private equity firm will not deviate from investing if

$$
\Pi_{s}(\tilde{F} \mid \cdot)=\frac{1}{4} F-\Psi>0=\Pi_{s}(F \mid \cdot)
$$


in which a private equity firm alone is successful in acquiring the restructuring skills with probability $1 / 4$ and $F$ is the net gain $\left(\bar{v}_{s}-S^{1}\right)$ from obtaining the target at a price $S^{1}=$ $\bar{v}_{s}-F$ (the valuation of the other unsuccessful private equity firm is $\bar{v}_{s}-F$, so this will be the equilibrium buyout price). The bars above the valuations denote valuations absent restructuring costs $F$. From equation (22), if the restructuring costs are sufficiently large $F>4 \Psi$ a private equity firm will stick with investing in acquiring specialized restructuring skills $(\tilde{F})$.

Now consider the incumbents. Let $\Pi_{k}(F \mid \tilde{F}, \tilde{F}, F)$ be the expected profit for an incumbent firm of choosing not to invest $(F)$ when the private equity firms choose to invest $(\tilde{F})$, but the rival incumbent does not invest. Let also $\Pi_{s}(\tilde{F} \mid \tilde{F}, \tilde{F}, F)$ be the expected profit from deviating investing in acquiring specialized restructuring skills. The expected profit from not investing is

$$
\Pi_{k}(F \mid \cdot)=\frac{3}{4} R_{N A}\left(\mu_{s}^{*}\right)+\frac{1}{4} \underbrace{\frac{1}{2}\left(R_{A}\left(\mu_{k}^{*}\right)-\Gamma\left(\mu_{k}^{*}\right)-F-\left(\bar{v}_{s}-F\right)\right)+\frac{1}{2} R_{N A}\left(\mu_{k}^{*}\right)}_{\text {Expected profit under incumbent acquisition }}],
$$

in which the probability that at least on private equity firm succeeds is $3 / 4$, and the probability that none of the private equity firms succeeds is $1 / 4$. In the latter case, there will be an incumbent acquisition at price $\bar{v}_{s}-F$ and an incumbent becomes the acquirer with probability $1 / 2$.

Now turn to the profit for an incumbent if it chooses to invest in acquiring specialized restructuring skills. If it does, it fails to learn anything new with probability $1 / 2$ and succeeds with probability $1 / 2$. In the latter case, the incumbent will buy the target at the price $S^{1}=\frac{3}{4} \bar{v}_{s}+$ $\frac{1}{4}\left(\bar{v}_{s}-F\right)=v_{s}-\frac{F}{4}$, since with probability $3 / 4$ at least one private equity firms succeeds and the incumbent pays this firm's valuation $\bar{v}_{s}$. Since an incumbent fails to obtain a low restructuring cost with probability $1 / 2$ and succeeds with probability $1 / 2$, the expected profit from investing is

$$
\Pi_{k}(\tilde{F} \mid \cdot)=\frac{1}{2} \frac{3}{4} R_{N A}\left(\mu_{s}^{*}\right)+\frac{1}{2}[\underbrace{\left(R_{A}\left(\mu_{k}^{*}\right)-\Gamma\left(\mu_{k}^{*}\right)-\left(\bar{v}_{s}-\frac{F}{4}\right)\right.}_{\text {Expected profit under acquisition }}]-\Psi .
$$

From equation (23) and equation (24), we can now examine when incumbents choose not to invest. With some manipulation we can derive the following condition

$$
\Pi_{k}(F \mid \cdot)-\Pi_{k}(\tilde{F} \mid \cdot)=\frac{1}{16}[\underbrace{\bar{v}_{s}-\bar{v}_{k k}}_{(+)}-7 \underbrace{\left(\bar{v}_{k s}-\bar{v}_{s}\right)}_{(+)}-2 F]+\Psi>0
$$

From equation (22) and equation (25), the following two conditions must hold in a asymmetric Nash-equilibrium $\left(F_{s_{1}^{*}}, F_{s_{2}^{*}}, F_{k_{1}^{*}}, F_{k_{2}^{*}}\right)=(\tilde{F}, \tilde{F}, F, F)$, in which private equity firms invest in acquiring restructuring skills while the incumbents choose not to invest:

$$
\begin{gathered}
F>4 \Psi, \text { and } \\
F<\Sigma+8 \Psi .
\end{gathered}
$$




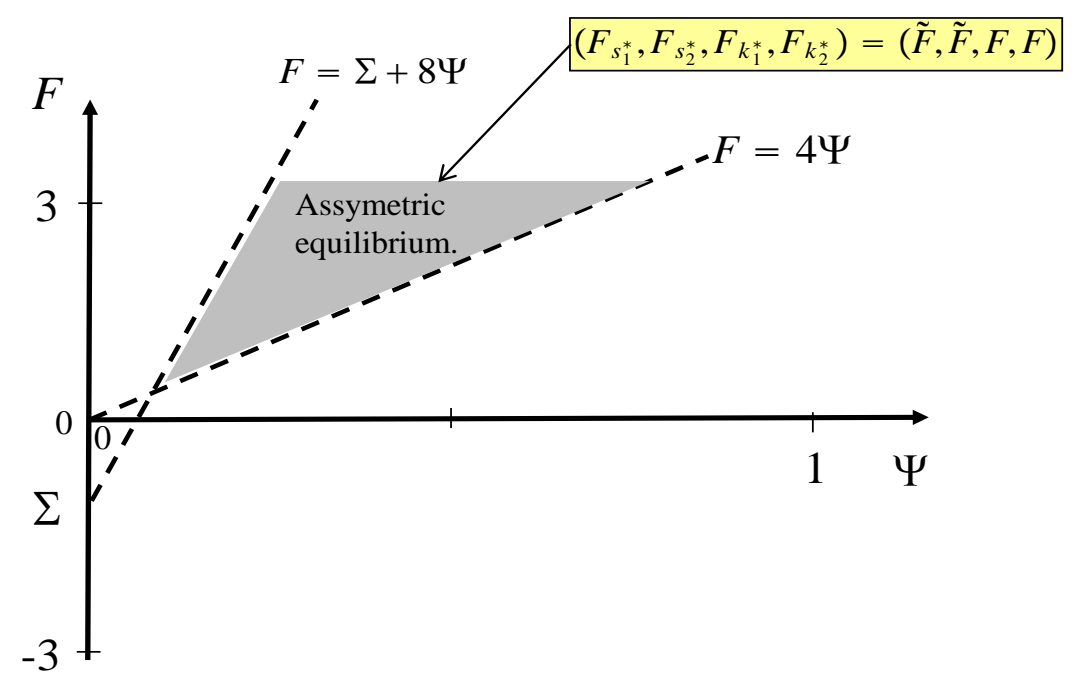

Figure 3: Illustrating the assymetric equilibrium in which only private equity firms that do not already have assets in the market invest in acquiring specialized restructuring skills.

The upper line gives the condition for a private equity firm to choose $\tilde{F}$, while the lower line gives the condition for incumbents to choose $F$. In the lower line, $\Sigma=\bar{v}_{s}-\bar{v}_{k k}-7\left(\bar{v}_{k s}-\bar{v}_{s}\right)$ is likely to be negative because incumbents have incentives to preempt private equity firms.

Figure 3 illustrates the condition in equation (26) in the $\Psi-F$ space using the linear quadratic Cournot model to calculate $\Sigma$. As can be seen, in order to have private equity firms choose to invest in acquiring restructuring skills, the costs $F$ must high relative in relation to the investment cost $\Psi$. This occurs above the locus $F=4 \Psi$. Intuitively, a higher restructuring cost $F$ causes a higher reward to succeeding since the acquisition price paid by the private equity firm $S^{1}=\bar{v}_{s}-F$ decrease in $F$. However, fixed restructuring costs cannot be too high since it will then profitable for incumbents to choose to invest in acquiring restructuring skills as well. An incumbent firm choosing to invest would pay the expected price $S^{1}=\bar{v}_{s}-F / 4$, which is also decreasing in the restructuring cost $F$.

Hence, an asymmetric equilibrium exists in which private equity firms invest in acquiring skills to restructure firms, while incumbents choose not to make this investment.

Proposition 3 If private equity firms and incumbents can choose to invest in acquiring specialized restructuring skills prior to bidding for the target's assets in stage one, there exists an asymmetric equilibrium in which private equity firms specialize at restructuring and outbid incumbents with a positive probability in the acquisition auction in stage one.

It is tedious, yet simple, to show that if agents were allowed to endogenously select whether to enter the market and acquire assets (become an incumbent) or stay out of the market (and become private equity firms), the asymmetric equilibrium we identify above would still be present. In the example with two incumbents and two private equity firms, $F>4 \Psi$ would be a necessary condition for private equity firms to emerge in equilibrium. 
In a more extended setting, private equity firms could repeatedly make use of their restructuring skills. Private equity firms then have incentives to exit their investments and look for new restructuring opportunities once they are finished with the assets they currently hold. As Muscarella and Vetsuypens (1990) note: "Exit strategies are important because LBO specialists' unique expertise lies in their ability to oversee the efficient restructuring of operations. Once such restructuring is largely accomplished in a given firm, the LBO specialist's marginal productivity will be higher if it redeploys capital and efforts elsewhere."

\subsubsection{Exogenous cost advantages}

Compared to incumbents, private equity firms may have cost advantages giving them the ability to acquire assets in equilibrium. Since they are repeat players in the debt markets and raise money from institutional investors, they have easier access to capital. This lowers their costs of financing both the deal and restructuring the assets compared to incumbents, who are more likely to be financially constrained.

Private equity firms are often also claimed to face preferential tax treatment because of their legal status as partnerships, and because of interest rate deductibility laws that allows private equity backed firms to benefit from a tax shield of debt. Badertscher et al. (2009) empirically document that majority owned private equity backed firms face substantially lower marginal tax rates as a result of the tax shield of debt. Kaplan (1989b) has also shown empirically that interest deductibility benefits equal $21 \%$ of the premium paid in buyout transactions, whereas incremental depreciation tax benefits from marking up assets to market value equals $28 \%$ of the premium paid.

To capture this formally, assume that private equity firms face exogenously lower fixed operating costs associated with acquiring and running the firm, $G_{h}$, such that $G_{s}<G_{k}$. The compensation given to the manager is then

$$
w_{h}=b+\mu\left[R_{A}(r)-F+\varepsilon-G_{h}\right] \quad h=s, k .
$$

Equation (21), determining if a buyout takes place, then becomes

$$
v_{k s}-v_{s}=R_{A}\left(\mu_{k}^{*}\right)-\Gamma\left(\mu_{k}^{*}\right)-\left[R_{A}\left(\mu_{s}^{*}\right)-\Gamma\left(\mu_{s}^{*}\right)\right]-\left[G_{k}-G_{s}\right] .
$$

This expression can be both positive and negative. If $G_{k}-G_{s}$ is sufficiently large, private equity firms are able to outbid incumbents in equilibrium despite the preemptive motive incumbents have.

If cost advantages arise in the variable costs of restructuring the firm, the analysis becomes more intricate but the main results hold true. Suppose that in addition to the fixed restructuring $\operatorname{costs} F$, the incumbents and the private equity firm face variable costs of $f_{h}(r)$, for $h=s, k$ with $f_{s}^{\prime}=d f_{s}(r) / d r<f_{k}^{\prime}=d f_{k}(r) / d r$ and $f_{s}^{\prime \prime}=d^{2} f_{s}(r) / d r^{2}<f_{k}^{\prime \prime}=d^{2} f_{k}(r) / d r^{2}$. Now it is 
no longer true that the effect of an increase in the managerial ownership share $\mu$ is the same if the assets are incumbent owned as it is when the assets are owned by a private equity firm. The reason is that $r_{h}^{*}(\mu)$ now depends on $h$ and becomes

$$
\mu \frac{d R_{A}}{d r}=C^{\prime}\left(r_{h}^{*}(\mu)\right)+f_{h}^{\prime}\left(r_{h}^{*}(\mu)\right) \quad h=s, k
$$

It must then hold that $\frac{d r_{s}^{*}}{d \mu}>\frac{d r_{k}^{*}}{d \mu}>0$. We delegate the details of this full analysis to the Appendix, but we can show that exogenous variable cost advantages for private equity firms will induce more high powered incentive contracts for managers in private equity backed firms, which lead to more intense restructuring even when product market effects are absent. Product market effects, however, amplify the differences in the intensity of the compensation contract and restructuring.

In spite of this, variable cost advantages for private equity firms can cause buyouts to occur in equilibrium. Equation (21) determining if a buyout takes place now becomes

$$
\left.\left.\left.\hat{v}_{k s}-\hat{v}_{s}=R_{A}\left(r_{k}^{*}\left(\hat{\mu}_{k}\right)\right)-\Gamma_{k}\left(r_{k}^{*}\left(\hat{\mu}_{k}\right), \hat{\mu}_{k}\right)\right)-\left[R_{A}\left(r_{s}^{*}\left(\hat{\mu}_{s}\right)\right)\right)-\Gamma_{s}\left(r_{s}^{*}\left(\hat{\mu}_{s}\right), \hat{\mu}_{s}\right)\right)\right] .
$$

Since $\hat{\mu}_{k}=\arg \max _{\mu}\left[R_{A}\left(r_{k}^{*}(\mu)\right)-\Gamma_{k}\left(r_{k}^{*}(\mu), \mu\right)\right]$, a preemptive acquisitions could occur $\left(\hat{v}_{k s}-\hat{v}_{s}>0\right)$. However, the variable cost advantage of private equity firms makes total costs lower for a given contract $\left(\Gamma_{s}(\mu)<\Gamma_{k}(\mu)\right)$. If private equity firms do not give managers "too intense" contracts compared to incumbents, $\hat{v}_{s}-\hat{v}_{k s}>0$ can hold. This is illustrated in Figure 4 , in which lower variable costs for private equity firms shift the solid lines to the dotted lines, implying that $\hat{v}_{s}-\hat{v}_{k s}>0$.

\subsubsection{Coordination failures}

Coordination failures can be a reason for why buyouts take place in equilibrium. From the discussion following Proposition 2, it follows that the gains from a direct preemptive acquisition by an incumbent in stage one are unevenly distributed among incumbents. In particular, the acquiring incumbent bears the cost of the preemption, while the other incumbents can free-ride on the acquisition:

$$
\underbrace{R_{N A}\left(\mu_{k}^{*}\right)}_{\text {Non-acquiring incumbent. }}>\underbrace{R_{A}\left(\mu_{k}^{*}\right)-\Gamma\left(\mu_{k}^{*}\right)-v_{s}}_{\text {Acquiring incumbent paying } S^{3}=v_{s} .}>\underbrace{R_{N A}\left(\mu_{s}^{*}\right)}_{\text {Incumbents if buyout occurs. }}
$$

This can cause a coordination failure between incumbents. Private equity firms can then outbid the incumbents even though $v_{k s}>v_{s}$. This can be shown by extending the auction in stage one to mixed strategy equilibria. In a mixed strategy equilibrium, incumbents can bid $v_{s}$ with probability $\rho^{*}$ and abstain from bidding with probability $1-\rho^{*}$, whereas private 


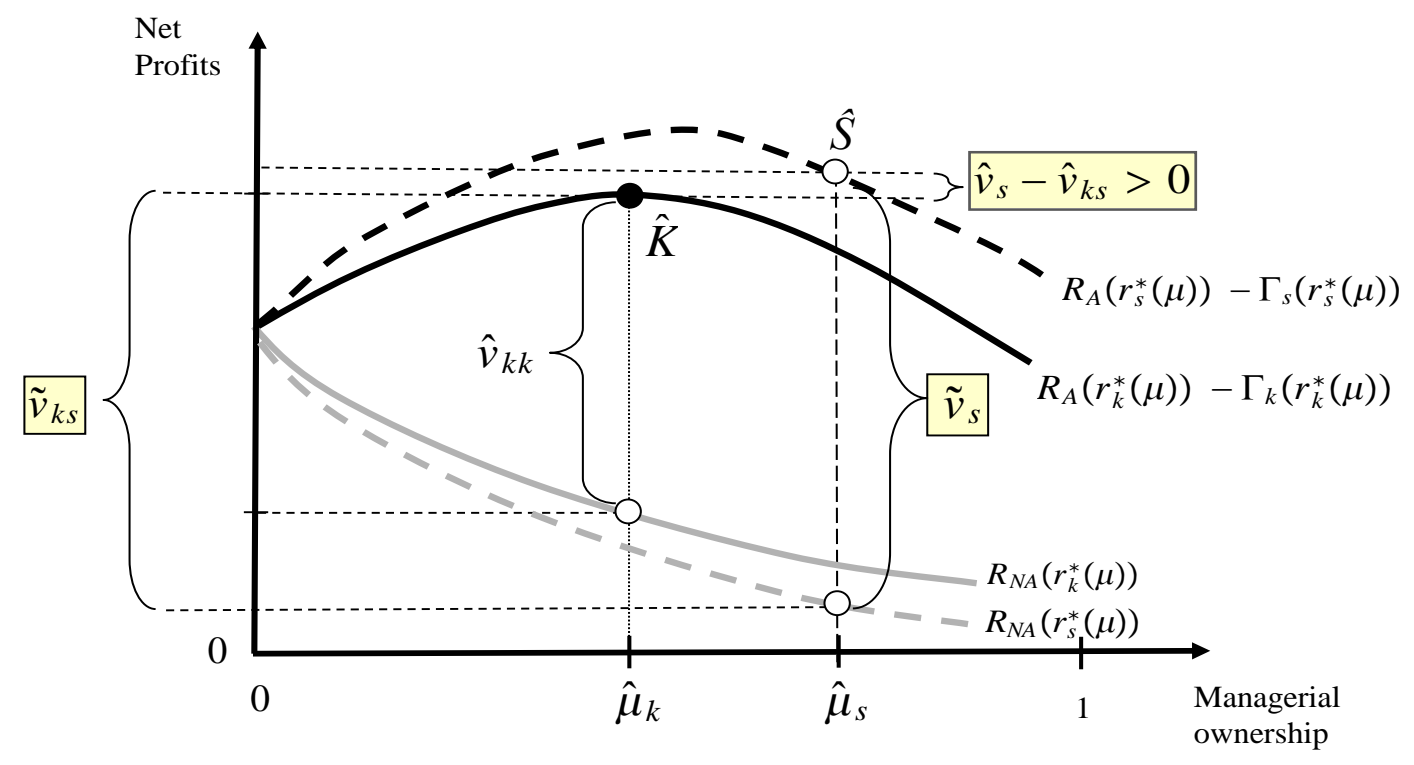

Figure 4: This figure illustrates the valuations in stage one if variable costs of restructuring differ between incumbents and private equity firms. Lower variable costs for private equity firms shift the solid lines to the dotted lines, implying that $\hat{v}_{s}-\hat{v}_{k s}>0$ and that a buyout can take place in equilibrium.

equity firms always bid their maximum valuation $v_{s}$. There are two possible outcomes. In the first, at least one incumbent bid $v_{s}$ and a preemptive acquisition takes place. In the second, no incumbents bid for the assets and a private equity firm obtains them at price $v_{s}$. Consequently, if incumbents fail to coordinate who should outbid the private equity firms, buyouts occur in equilibrium.

\subsection{Welfare effects of buyouts: the case of merger policy}

Let us end this section on the equilibrium emergence of private equity firms with a note on the welfare effects of buyouts. The conventional welfare evaluation in a merger analysis is typically made by comparing the sum of consumer surplus and profits (including the sales price of the target) in different market structures. We adhere to this approach and compare welfare under an incumbent acquisition to welfare if a buyout takes place.

Consider a setting in which private equity firms face fixed restructuring costs of fixed costs $F_{s}$ and incumbents face fixed costs $F_{k}$. To simplify, no manager needs to be hired; the owners can directly set $r$ at cost $C(r)$. Consumer surplus, $C S(r)$, increases in restructuring intensity: $C S^{\prime}(r)>0$, and $W_{s}$ is total welfare under a buyout and $W_{k}$ is total welfare under an incumbent acquisition.

If a buyout occurs, compared to an incumbent acquisition, the acquirer's profits and con- 
sumer surplus is larger, but non-acquirers' profits are smaller:

$$
\begin{aligned}
W_{s}-W_{k} & =\underbrace{R_{A}\left(r_{s}^{*}\right)-C\left(r_{s}^{*}\right)-F_{s}+(n-1) R_{N A}\left(r_{s}^{*}\right)+C S\left(r_{s}^{*}\right)}_{W_{s}} \\
& -\underbrace{\left[R_{A}\left(r_{k}^{*}\right)-C\left(r_{k}^{*}\right)-F_{k}+(n-1) R_{N A}\left(r_{k}^{*}\right)+C S\left(r_{k}^{*}\right)\right]}_{W_{k}} \\
& =\underbrace{\left[R_{A}\left(r_{s}^{*}\right)-C\left(r_{s}^{*}\right)\right]-\left[R_{A}\left(r_{k}^{*}\right)-C\left(r_{k}^{*}\right)\right]-\left[F_{s}-F_{k}\right]}_{v_{s}-v_{k s}>0} \\
& +\underbrace{C S\left(r_{s}^{*}\right)-C S\left(r_{k}^{*}\right)}_{>0}+(n-1) \underbrace{\left[R_{N A}\left(r_{s}^{*}\right)-R_{N A}\left(r_{k}^{*}\right)\right]}_{<0} .
\end{aligned}
$$

The total effect on welfare is ambiguous, but overinvestment (from the point of view of incumbents) by private equity firms in restructuring is good for consumers. However, overinvestment hurts non-acquiring incumbents and also brings with it increased restructuring costs.

Moreover, allowing the initial market structure to be stable, i.e. the target firm to be sufficiently efficient, it can be shown in an extended model that an active private equity market can ignite the process of creative destruction by triggering mergers and restructuring in an initially merger-stable industry. In fact, the mere threat of a private equity buyout can cause a preemptive incumbent acquisition that takes place to prevent aggressive restructuring by a private equity firm. Total welfare can increase or decrease. Restructuring increases productivity and thereby raises the profits of the possessor and consumers, but it reduces the profits of rivals. The industry also becomes more concentrated leading to an increase in incumbents' profits and a decrease in consumer surplus. A private equity buyout compared to a direct incumbent acquisition, however, unambiguously benefits consumers but hurt incumbents; aggressive restructuring by the private equity firm benefits consumer through lower prices but hurts incumbents due to a tougher bidding competition for the restructured assets. A discriminating merger policy against private equity buyouts would thus be counterproductive, since most jurisdictions have consumer welfare as the goal of the merger policy.

\section{Extensions and Robustness}

We have now set up our model and shown that private equity firms buying to sell have incentives to induce more restructuring compared to incumbents buying to keep, and thereby give managers more ownership in the firm. We have also demonstrated that incumbents have incentives to preemptively outbid private equity firms to prevent intense restructuring of the assets. Buyouts occur in equilibrium if incumbents fail to coordinate bidding, if private equity firms have exogenous cost advantages, or if private equity firms have successfully acquired superior restructuring skills.

In this section, we discuss robustness and offer a set of extensions to our framework. Section 
4.1 allows incumbents to buy assets in order to sell them. This extension does not significantly alter our results. Our results are also not affected if the manager's incentive contract is based on the trade sale price instead of on product market profits (section 4.2). In section 4.3 we study debt as an incentive mechanism, and show that high leverage in private equity backed firms can be a consequence of buying to sell. In section 4.4 we briefly study the choice between a trade sale and an IPO, describing how not too convex restructuring costs and high IPO costs lead private equity firms to favor a trade sale over an IPO. We end this section by discussing other potential selling mechanisms for assets apart from a first price perfect information auction.

\subsection{Incumbents buying to sell}

Our model assumes that incumbents buy assets to keep them, whereas private equity firms buy assets to sell them. Would our results still hold if incumbents could imitate private equity firms and also buy to sell?

Suppose that an incumbent acquired the target in stage one and that the incumbent attempts to sell the restructured assets to a competitor. From Lemma 1, we know that the trade sale price in stage three is $S^{3}=R_{A}(\mu)-R_{N A}(\mu)$. We also know the profits from competing with a rival who possesses the assets are $R_{N A}(\mu)$. Thus, the total profits from selling the assets and remaining in the industry would be $S^{3}+R_{N A}(\mu)$. Working through the contract for a hired manager in stage two, the expected profit an incumbent mimicking a private equity firms the exactly the same as in equation (13):

$$
\mathrm{E}\left[S^{3}(\mu)-F+\varepsilon-w(b, \mu)+R_{N A}(\mu)\right]=R_{A}(\mu)-\Gamma(\mu)
$$

From equation (33) it is clear that an incumbent buying to sell gives the same optimal contract as an incumbent buying to keep: $\left\{\mu_{k}^{*}, b_{k}^{*}\right\}$. But then, propositions 1 and 2 still hold. The key to why the incumbent does not become as aggressive as a private equity firm is that the incumbent internalizes the effect on its other asset holdings when setting the compensation contract that determines restructuring intensity.

But cannot the incumbent sell all of its assets and completely exit the industry? This is possible, but if it is profitable or not will depend on the classical merger profitability condition (Salant et al., 1983). In our setting, a full exit by an incumbent committed to sell occurs if the following condition holds:

$$
\underbrace{R_{A}\left(\mu_{s}^{*} ; n-1\right)-R_{N A}\left(\mu_{s}^{*} ; n-1\right)-\Gamma\left(\mu_{s}^{*}\right)}_{\text {Profits from selling (with concentration effect), } v_{s}}>\underbrace{R_{A}\left(\mu_{k}^{*} ; n\right)-\Gamma\left(\mu_{k}^{*}\right)}_{\text {Profits from keeping }},
$$

An exit leads to a concentration of the market since there are only $n-1$ incumbents remaining in the market.

In general, the sign of equation (34) depends on merger and market-specific characteristics 
such as level of concentration in the market and asset complementaries. For example, if the asset complementaries are sufficiently low, and the market power increase caused by the merger is sufficiently low, the incumbent will not have the incentives to completely exit the industry.

\subsection{Incentive contracts based on the trade sale price}

In the main analysis, we assumed that the manager was given a share of the product market profits $\left(R_{A}(r)\right)$ net restructuring costs. This enables us to compare the intensity of the compensation contract for the two ownership types. It is also consistent with many contracts used in practice as managers in private equity backed firms are often required to remain with the target (or are forced to keep their stocks in the firm) post exit in order to reduce problems associated with, for example, window dressing.

However, if the manager is allowed to sell all shares at the time of exit, the relevant share for the manager is a share of the trade sale price instead of a share of the product market profits. Can this affect our results?

Suppose that in stage two the private equity firm gives the manager a contract $\{\mu, b\}$ in which the equity share $\mu$ now specifies a share of the trade sale price $S^{3}(r)=R_{A}(r)-R_{N A}(r)$ net of restructuring costs. The wage compensation given to the manager is then

$$
w=b+\mu\left[R_{A}(r)-R_{N A}(r)-F+\varepsilon\right]
$$

Working through the manager's optimization problem, we find that the manager's first-order condition when setting the restructuring intensity is

$$
\mu\left[\frac{d R_{A}}{d r}-\frac{d R_{N A}}{d r}\right]=\frac{d C\left(r_{s}^{*}(\mu)\right)}{d r} .
$$

Under incumbent ownership, managerial compensation is still based on a share of the product market profit and the optimal restructuring by the manager is still given from equation (11). Comparing equation (36) and (11), it is evident that the effect on non-acquirers $\left(\frac{d R_{N A}}{d r}<0\right)$ implies $r_{s}^{*}(\mu)>r^{*}(\mu)$. This means that a manager in a private equity firm buying to sell will undertake more restructuring than a manager in an incumbent firm buying to keep for a given share $\mu$. This is shown in Figure 5(i).

From equation (36) and (11), the manager in a private equity backed firm also reacts more strongly to an increase in the ownership share $\mu$ :

$$
\frac{d r_{s}^{*}}{d \mu}=-\frac{R_{A}^{\prime}-R_{N A}^{\prime}}{\mu\left[R_{A}^{\prime \prime}-R_{N A}^{\prime \prime}\right]-C^{\prime \prime}}>-\frac{R_{A}^{\prime}}{\mu R_{A}^{\prime \prime}-C^{\prime \prime}}=\frac{d r^{*}}{d \mu}>0 .
$$

Here we assume that the second-order conditions $\mu\left[R_{A}^{\prime \prime}-R_{N A}^{\prime \prime}\right]-C^{\prime \prime}<0$ and $\mu R_{A}^{\prime \prime}-C^{\prime \prime}<0$ are fulfilled, and that $R_{A}(r)$ and $R_{N A}(r)$ are convex or not too concave. The manager is also 
(i) Investments into restructuring in late stage 2

(ii) Managerial ownership in early stage 2

(iii) Valuations for the target $t$ in stage 1.

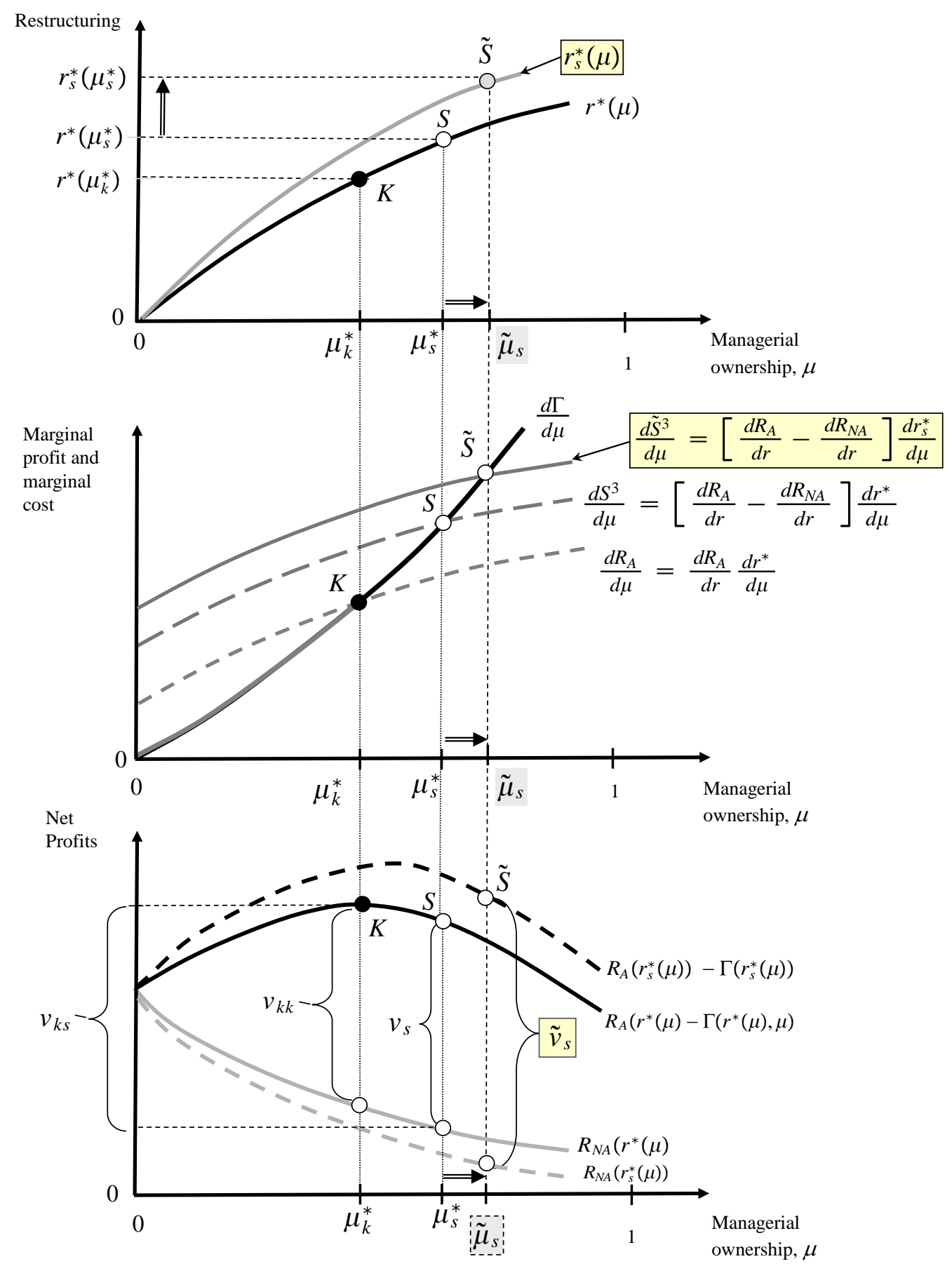

Figure 5: This illustrates the solution for stage one and two of the game when the manager is offered a share of the trade sale price instead of a share of product market profits. The manager then reacts stronger to increased managerial ownership, however it is still optimal for private equity firms to give managers larger ownership shares than what incumbents give their managers. 


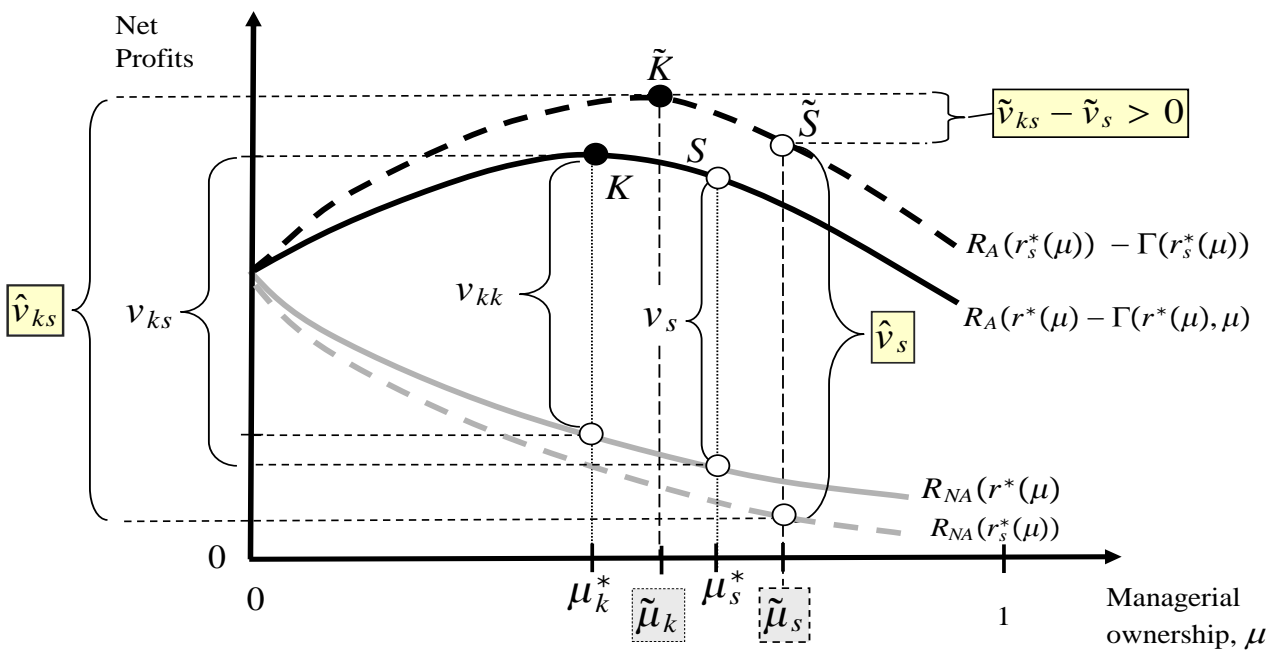

Figure 6: This illustrates the solution to Stage one when an incumbent offers the manager a "relative compensation contract" that mimics the contract a private equity firm offers. Even then, private equity firms use more intense compensation contracts and can not outbid incumbents.

more sensitive to an increase in the share is because of the effect on non-acquirers $\left(R_{N A}^{\prime}=\right.$ $d R_{N A} / d r<0$ ) of increased restructuring.

Consider now the optimal share to give the manager. The optimal ownership share for the incumbent remains unchanged at $\mu_{k}^{*}=\arg \max _{\mu}\left[R_{A}\left(r^{*}(\mu)\right)-\Gamma\left(r^{*}(\mu), \mu\right)\right]$. However, the optimal share for a manager in a private equity backed firm is now $\tilde{\mu}_{s}=\arg \max _{\mu}\left[R_{A}\left(r_{s}^{*}(\mu)-\right.\right.$ $\left.R_{A}\left(r_{s}^{*}(\mu)\right)-\Gamma\left(r_{s}^{*}(\mu), \mu\right)\right]$, with the first-order condition

$$
\left[\frac{d R_{A}}{d r}-\frac{d R_{N A}}{d r}\right] \frac{d r_{s}^{*}}{d \mu}=\Gamma^{\prime}\left(\tilde{\mu}_{s}\right)
$$

When the manager receives a share of the trade sale price, two effects causes stronger incentive contracts in private equity backed firms $\left(\tilde{\mu}_{s}>\mu_{k}^{*}\right)$. Private equity firms buying to sell have stronger incentives to induce restructuring since they maximize the trade sale price $S^{3}$. In addition, managers in private equity backed firms responds more vigorously to an increase in the share $\mu$ as shown in (37). This is illustrated in Figure 5(ii), in which $\tilde{\mu}_{s}>\mu_{k}^{*}$. Figures 5(i)-(ii) reveal that Proposition 1 holds in a setting in which private equity firms base incentive contracts on the trade sale price.

What about the equilibrium ownership structure determined in stage one? As shown in Figure 5(iii), by applying the ownership share for the manager on the trade sale price rather than on the product market profits, private equity firms can increase their valuation $v_{s}$ for acquiring the target since $\tilde{v}_{s}=R_{A}\left(r_{s}^{*}\left(\tilde{\mu}_{s}\right)\right)-R_{N A}\left(r_{s}^{*}\left(\tilde{\mu}_{s}\right)\right)-\Gamma\left(r_{s}^{*}\left(\tilde{\mu}_{s}\right), \tilde{\mu}_{s}\right)>v_{s}=R_{A}\left(r^{*}\left(\mu_{s}^{*}\right)\right)-$ $\left.R_{N A}\left(r^{*}\left(\mu_{s}^{*}\right)\right)-\Gamma\left(r^{*}\left(\mu_{s}^{*}\right), \mu_{s}^{*}\right)\right)$ holds from $r_{s}^{*}(\mu)>r^{*}(\mu)$. We are then assuming that $R_{A}\left(r_{s}^{*}(\mu)\right)-$ $\Gamma\left(r_{s}^{*}(\mu), \mu\right)>R_{A}\left(r^{*}(\mu)\right)-\Gamma\left(r^{*}(\mu), \mu\right)$, from $r_{s}^{*}(\mu)>r^{*}(\mu)$, meaning that the net profit of the acquirer increases from having the manager providing more restructuring. As also shown 
in Figure 5(iii), private equity firms can even outbid incumbents since $\tilde{v}_{s}>v_{k s}$ could hold.

But would incumbents have incentives to copy the compensation contract offered by private equity firms? Yes. Given the same compensation as in equation (35), incumbents would be able to outbid private equity firms when giving the manager a contract that mimics a contract on the trade sale price. This follows since $\tilde{\mu}_{k}=\arg \max _{\mu}\left[R_{A}\left(r_{s}^{*}(\mu)\right)-\Gamma\left(r_{s}^{*}(\mu), \mu\right)\right]<$ $\tilde{\mu}_{s}^{*}=\arg \max _{\mu}\left[R_{A}\left(r_{s}^{*}(\mu)-R_{A}\left(r_{s}^{*}(\mu)\right)-\Gamma\left(r_{k}^{*}(\mu), \mu\right)\right], \tilde{v}_{k s}=R_{A}\left(r_{s}^{*}\left(\tilde{\mu}_{k}\right)\right)-\Gamma\left(r_{s}^{*}\left(\tilde{\mu}_{k}\right), \tilde{\mu}_{k}\right)-\right.$ $R_{N A}\left(r_{s}^{*}\left(\tilde{\mu}_{s}\right)\right)$ and $\tilde{v}_{k s}-\tilde{v}_{s}=R_{A}\left(r_{s}^{*}\left(\tilde{\mu}_{k}\right)\right)-\Gamma\left(r_{s}^{*}\left(\tilde{\mu}_{k}\right), \tilde{\mu}_{k}\right)-\left[R_{A}\left(r_{s}^{*}\left(\mu_{s}^{*}\right)\right)-\Gamma\left(r_{s}^{*}\left(\mu_{s}^{*}\right), \mu_{s}^{*}\right)\right]>0$. Thus, as shown in Figure 6, Proposition 2 also holds in a setting in which private equity firms give the manager a share of the trade sale price and incumbents can copy this contract.

\subsection{Buying to sell and leverage}

Debt can also work as an incentive device substituting for (or complementing for) managerial ownership if debt forces the manager to work harder to avoid bankruptcy (e.g. Jensen and Meckling, 1976; Jensen 1986, 1989). When deciding on leverage, the owners trade off increased restructuring efforts against an increased probability of bankruptcy. As such, we can link buying to sell to the capital structure of the firms.

Let us replace managerial ownership with debt in our model to see how this would work. Formally, at the beginning of stage two, the owner of the target decides how much debt, $D$, to acquire and then hires a manager to undertake restructuring to increase $r$. The probability of surviving the restructuring stage is $\rho(r, D) \in[0,1], \rho_{r}^{\prime}(r, D)>0, \rho_{r r}^{\prime \prime}(r, D)<0, \rho_{D}^{\prime}(r, D)<0$ and $\rho_{r D}^{\prime \prime}(r, D)>0$. If the firm goes bankrupt during restructuring (with probability $1-\rho(r, D)$ ), profits are zero. Debt will not affect product market decisions, since incentive problems are only present in stage two of the game.

The manager receives a fixed wage $b$ if the firm survives and zero wage otherwise. The effort cost of $r$ to the manager is once more $C(r)$ with $C^{\prime}(r)>0$ and $C^{\prime \prime}(r)>0$, but the manager is no longer risk averse. Formally, given debt $D$, the manager sets $r$ to maximize $\rho(r, D) b-C(r)$, in which optimal restructuring is implicitly determined by

$$
\rho_{r}^{\prime}\left(r^{*}, D\right) b=C^{\prime}\left(r^{*}\right)
$$

with the associated second-order condition $\rho_{r r}^{\prime \prime} b-C^{\prime \prime}(k)<0$. The manager's restructuring effort $r^{*}$ increases in tact with leverage: $\frac{d r^{*}}{d D}=-\frac{\rho_{r D}^{\prime \prime} b}{\rho_{r r} b-C^{\prime \prime}}>0$.

An incumbent buying to keep maximizes the expected profit net of interest payments on debt (paid upon successful restructuring): $\rho\left(r^{*}(D)\right)\left[R_{A}\left(r^{*}(D)\right)-b-i D\right]$, in which $i$ is the interest rate. Optimal debt for an incumbent is implicitly determined by the first-order condition

$$
\underbrace{\frac{d \rho}{d D}\left[R_{A}-i D_{k}^{*}\right]}_{\text {Marginal cost of increased bankruptcy probability }}+\underbrace{\rho\left[\frac{d R_{A}}{d r^{*}} \frac{d r^{*}}{d D}-i\right]}_{\text {Marginal benefit of increased restructuring }}=0
$$


and $\frac{d \rho}{d D}=\rho_{r}^{\prime} \frac{d r^{*}}{d D}+\rho_{D}^{\prime}$ is the total derivative of debt on the probability of survival (we assume the second-order condition holds).

A private equity firm buying to sell maximizes the expected trade sale price net of interest payments on debt: $\rho\left(r^{*}(D)\right)\left[S^{3}\left(r^{*}(D)\right)-b-i D\right]$. The optimal amount of debt for a private equity backed firm is then given from the first-order condition

$$
\frac{d \rho}{d D}\left[S^{3}-r D_{s}^{*}\right]+\rho\left[\frac{d S^{*}}{d r^{*}} \frac{d r^{*}}{d D}-i\right]=0 .
$$

Rewrite equation (41) as

$$
\underbrace{\frac{d \rho}{d D}\left[R_{A}-i D_{s}^{*}\right]+\rho\left[\frac{d R_{A}}{d r^{*}} \frac{d r^{*}}{d D}-i\right]}_{\text {First-order condition for an incumbent }}+\underbrace{\left[-\rho \frac{d R_{N A}}{d r^{*}} \frac{d r^{*}}{d D}-\frac{d \rho}{d D} R_{N A}\right]}_{\text {Marginal effect on a non-acquirer (positive) }}=0 .
$$

A comparison of equation (40) and (42) shows that a private equity backed firm will take on more debt than an incumbent owned firm, i.e. $D_{s}^{*}>D_{k}^{*}$. The intuition is now familiar. A private equity firm maximizes the expected trade sale price, $\rho\left(r^{*}(D)\right)\left[S^{3}\left(r^{*}(D)\right)-b-i r^{*}(D)\right]$ rather than the expected reduced product market profits, $\rho\left(r^{*}(D)\right)\left[R_{A}\left(r^{*}(D)\right)-b-i r^{*}(D)\right]$. If debt is taken on to induce a manager to put more effort into restructuring, then private equity firms buying to sell optimally choose higher leverage than incumbents buying to keep.

\subsection{IPOs}

In our main analysis, a private equity firm sold the target to an incumbent after restructuring. There is a small but growing literature on the decision to go public versus being acquired (Brau et al., 2003; Poulsen and Stegemoller, 2008; Chemmanur and Bayar, 2009). The literature has so far has mostly concentrated on informational asymmetries. Introducing private equity firms to our model, we can show that private equity firms tend to exit through a trade sale instead of taking the targets public when IPO costs are high and restructuring costs are not overly convex.

Formally, suppose we allow the private equity firm to exit through an IPO (at IPO cost $F_{I P O}$ ) instead of selling the assets to an incumbent. To simplify, suppose the owners can directly set $r$ at a cost $C(r)$ and thereby sidestep hiring a manager to undertake restructuring.

If a buyout occurs, we need to determine three valuations: an incumbent's valuation of obtaining the target if another incumbent would otherwise have obtained it, the incumbents' valuations of obtaining the target if it would otherwise have been placed on the market through an IPO; and the valuation of the private equity firm undergoing an IPO.

An incumbent's valuation of obtaining the restructured target if it would otherwise be obtained by another incumbent is

$$
\omega_{k k}=R_{A}(r ; n)-R_{N A}(r ; n) .
$$


The incumbent's preemptive IPO valuation is defined as

$$
\omega_{k I P O}=R_{A}(r ; n)-R_{N A}(r ; n+1)
$$

which is the valuation of acquiring the restructured target if the private equity firm would otherwise have taken it public (an additional firm is on the market if an IPO occurs).

Finally, the private equity firm valuation of taking the firm public is

$$
\omega_{I P O}=R_{E}(r ; n+1)-F_{I P O}
$$

in which the first term is simply the product market profits of the target with one more firm on the market and the second term is the costs of taking the firm public. The equilibrium ownership of the restructured target and the trade sale/IPO price can be described by Table II (proof available upon request).

\begin{tabular}{cccc}
\hline Inequality: & Definition: & Exit route & Trade sale price/IPO revenues \\
$I 1:$ & $\omega_{I P O}>\max \left\{\omega_{k I P O}, \omega_{k k}\right\}$ & IPO & $\omega_{I P O}^{*}$ \\
$I 2:$ & $\omega_{k I P O}>\omega_{I P O}>\omega_{k k}$ & Trade Sale & $\omega_{I P O}^{*}$ \\
$I 3:$ & $\omega_{k k}>\omega_{I P O}>\omega_{k I P O}$ & Trade Sale & $\omega_{k k}^{*}$ \\
$I 4:$ & $\max \left\{\omega_{k I P O}, \omega_{k k}\right\}>\omega_{I P O}$ & Trade Sale & $\omega_{k k}^{*}$ \\
\hline
\end{tabular}

Table II: This table describes the exit route (IPO or trade sale) and the trade sale price/IPO revenues for any possible ranking of the valuations $\omega$.

In $I 3$ and $I 4$, the private equity firm exits through a trade sale at the trade sale price $\omega_{k k}^{*}$. A high IPO cost, $F_{I P O}$, ensures that we end up in these regions. So does also a "not too" convex restructuring cost function $C(r)$. Both $R_{N A}(r ; n)$ and $R_{N A}(r ; n+1)$ are decreasing in $r$. This means that $\omega_{k k}(r)$ and $\omega_{k I P O}(r)$ increase faster in $r$ than $\omega_{I P O}(r)$. Then, as we increase $r$, it is more likely that inequalities $I 3$ and $I 4$ hold. If $C(r)$ are "not too" convex, it can be shown that $r_{s}^{*} \in \arg \max _{r}\left[\omega_{k k}(r)-C(r)\right]$ will be larger than $r_{s}^{I P O} \in \arg \max _{r}\left[R_{E}(r ; n+1)-C(r)-F_{I P O}\right]$ and this means that inequalities $I 3$ and $I 4$ are more likely to hold and that the optimal exit mode is a trade sale.

\subsection{Other selling mechanisms}

Let us end this section by relating this result to the literature on endogenous ownership and efficiency. Coase (1960) argued that in a zero-transaction world, laissez-faire always leads to optimal outcome irrespective of assignment of property rights. We have argued in this paper that if assets are sold though auctions, and if investment in the assets are possible, the equilibrium amount of investment will be too high (despite that the assets end up with the most 
efficient owner). This is the case because private equity firms that buy to sell have an incentive to overinvest in relation to the eventual owner's first best.

In the analysis, we have assumed that the seller of the target firm uses a first-price sealed bid auction. We believe this auction set-up accurately approximates bidding competition in oligopolies. But some possibilities for creating additional rents are neglected as a result. More generally, Jehiel, Moldovanu and Stacchetti (1999) show that sophisticated mechanisms are needed to maximize revenues in auctions with externalities; it could be that all firms in the market need to provide transfers to the seller. However, as pointed out by Jehiel and Moldovanu (2000), the seller needs an unrealistically strong commitment power making such mechanisms impractical. One feasible way for the target firm to extract more rents is to threaten to commit to sell to a private equity firm that will aggressively restructure the assets. An incumbent firm would be willing to pay $v_{k s}$, which would give the target firm larger proceeds compared to when it sells to a private equity firm (since $S^{1}=v_{s}<v_{k s}$ ).

One way of achieving this would be to state a reservation price of $v_{k s}$, but this will not work unless the target can restructure its own assets. The reason is that if the reservation price is $v_{k s}>v_{s}$, private equity firms will not participate in the auction and the threat of selling to one of them will not be credible. The maximum willingness to pay for incumbents would then be $v_{k k}$ and the target firm would be forced to charge a reservation price lower than $v_{k s}$.

\section{Empirical implications}

Let us now collect a set of empirical implications and relate them to available empirical evidence.

First, Proposition 1 states that managers in private equity backed firms will be given more high powered incentive contracts than managers in incumbent owned firms, i.e. $\mu_{s}^{*}>\mu_{k}^{*}$. Consequently, managers in private equity backed firms in oligopolistic industries have stronger incentive contracts than managers in incumbent firms. This prediction is consistent with existing evidence, although existing evidence does not separate between more and less oligopolistic industries. For example, Kaplan (1989a); Jensen and Murphy (1990); Kaplan and Strömberg (2009); Leslie and Oyer (2008) and Acharya and Kehoe (2008) find that targets owned by private equity firms have managers with stronger incentive contracts and a larger ownership share in the firm.

Second, Proposition 1 also states that more restructuring is undertaken in private equity backed firms than in incumbent firms $\left(r^{*}\left(\mu_{s}^{*}\right)>r^{*}\left(\mu_{k}^{*}\right)\right)$ leading to higher product market profits $\left(R_{A}\left(\mu_{s}^{*}\right)>R_{A}\left(\mu_{k}^{*}\right)\right)$ and higher productivity. Hence we can state that private equity backed firms in oligopolistic industries undertake more restructuring than incumbents, which results in higher product market profits and higher productivity. This prediction is also consistent with existing evidence on buyouts in general (but again, evidence does not separate between more and less oligopolistic industries). For example, Lichtenberg and Siegel (1990); Amess (2002, 
2003) and Harris et al. (2005) find evidence that buyouts increase the productivity of targets.

Third, our model shows that private equity backed firms will restructure assets beyond the level that would maximize an incumbent's profits. This higher level of investment explains that targets restructured by private equity firms have better long-run operational performance than incumbents. However, the net profit of the acquirer (including the acquisition price) will be lower in industries in which private equity is present compared to industries with no private equity firms, since the acquisition price of the target will be higher. Proposition 1 states that more restructuring is undertaken in private equity backed firms than in incumbent firms $\left(r^{*}\left(\mu_{s}^{*}\right)>r^{*}\left(\mu_{k}^{*}\right)\right)$. This means that product market profits are lower for non-acquirers: $R_{N A}\left(\mu_{s}^{*}\right)<R_{N A}\left(\mu_{k}^{*}\right)$. Hence we can state that in oligopolistic industries with heavy involvement of private equity firms should be less profitable than industries with less private equity involvement.

Fourth, in section 4.3, we derived a prediction for leverage by replacing managerial ownership with debt as a way of inducing managerial effort (Jensen 1986, 1989). Thus we can directly state that private equity backed firms in oligopolistic industries will be more leveraged. Evidence is found in, for example, Axelson et al. (2009) and Leslie and Oyer (2008). Axelson et al. (2009) report that there is no evidence of correlation in debt levels between private equity owned firms and similar firms that are not private equity owned. Our model predicts a correlation, although no correlation is consistent with our model if the optimal amount of debt for private equity firms is larger than the maximum amount banks are willing to lend. Then, private equity firms will borrow all they can until they hit the constraint set by the banks, and there will appear to be no correlation between debt levels of incumbents and private equity backed firms.

Fifth, in section 4.4, we derived predictions on the mode of exit. In particular, we can state that for private equity backed firms in oligopolistic industries, the optimal exit mode is a trade sale if IPO costs are high, or if restructuring costs are not too convex. Moreover, the trade sale price is more sensitive to restructuring than the IPO valuation which has implications for the characteristics of targets that will be exited through a trade sale. Firms that exited through a trade sale should be more restructured and should therefore have higher product market profits and productivity. To our knowledge, no systematic econometric work has been done on how the exit mode for private equity depends on IPO costs, on restructuring costs, and on cost and demand shocks. However, Lerner (1994) and Brau et al. (2003) find that market timing affects the mode of exit for venture capital exits.

\section{Concluding remarks}

We have studied private equity firms that buy to sell in oligopolistic markets, showing that buying to sell gives incentives to overinvest in restructuring. This leads to higher leverage and larger managerial ownership in target firms, two hallmarks of the private equity business model. Our key insight is that buying to sell makes private equity firms more aggressive in 
restructuring, since the equilibrium trade sale price increases in restructuring not only by raising the product market profits of the acquirer, but also by decreasing the product market profits of non-acquiring firms. To be valid, our mechanism essentially only requires that there is a focus on buying to sell, a trade sale exit is considered, and that at least two firms from the same industry bid for the private equity backed target in the exit auction.

As such, we argue that private equity firms fill an important role as challengers of existing oligopolies through aggressive restructuring of assets up for sale. The welfare effects of buyouts are ambiguous, but consumers always gain from a buyout as opposed to an acquisition by an incumbent firm. By being outsiders without assets in the market, private equity firms have stronger incentives than incumbents to invest in acquiring restructuring skills. These skillspotentially in combination with tax advantages, easy access to capital, and coordination failures among incumbents-subsequently allow them to outbid incumbents wanting to preemptively acquire the assets to prevent overinvestment in restructuring.

We believe there are other market situations apart from product market effects in which owners buying to sell have fundamentally different incentives than owners buying to keep. To see this, suppose an owner (who is buying to keep or buying to sell) undertakes an investment, $\delta$, in an asset. Both owner types face the same investment costs $c(\delta)$. The investment leads to a discounted stream of profits for the eventual owner of the asset. It then follows that as long as the marginal effect on the sale price, $S^{\prime}(\delta)$, equals the marginal effect on the long-run value, $V^{\prime}(\delta)$, the owner buying to sell and the owner buying to keep will undertake the same investment $\left(\delta_{s}=\delta_{k}\right)$. But as shown in the analysis above, if there are oligopolistic externalities on the trade sale price it holds that $S^{\prime}(\delta)>V^{\prime}(\delta)$ and the owner buying to sell will invest more $\left(\delta_{s}>\delta_{k}\right)$.

Other market situations could cause buy to sell owners to have different investment incentives than buy to keep owners. For example, appropriability problems in connection with the sale affect investment in patents. An owner buying to keep prefers to keep most of her important innovations as trade secrets, whereas an owner buying to sell must patent them to keep potential buyers from stealing the secrets. Reputation is also important. Owners buying to sell often have to repeatedly raise funds from outside investors for their investments. For these investors, the exit sends a signal about the quality of the owner. A good signal makes it easier to raise the next fund, implying that owners buying to sell have additional incentives to perform well. This affects the sale price $S(\delta)$, but not the long-run value $V(\delta)$. Examining these different issues related to buying assets with the intent of selling them is an exciting avenue for future research. 


\section{A Appendix}

\section{A.1 Proof of Lemma 1}

Consider the equilibrium candidate $b^{*}=\left(b_{1}^{*}, b_{2}^{*}, \ldots, b_{n}^{*}\right)$. Incumbent $f$ is the incumbent that has posted the highest bid and obtains the restructured target and firm $s$ is the incumbent with the second highest bid. Then, $b_{f}^{*} \geq \omega_{k k}$ is a weakly dominated strategy. $b_{f}^{*}<\omega_{k k}-\varepsilon$ is not an equilibrium, since firm $i \neq f$ then benefits from deviating to $b_{i}=b_{f}^{*}+\varepsilon$, since it will then obtain the restructured target and pay a price lower than its valuation of obtaining it. If $b_{f}^{*}=\omega_{k k}-\varepsilon$, and $b_{s}^{*} \in\left[\omega_{k k}-\varepsilon, S-2 \varepsilon\right]$, then no incumbent has an incentive to deviate, $b^{*}$ is a Nash equilibrium and the winning bid is $b_{f}^{*}=\omega_{k k}-\varepsilon$.

\section{A.2 Proof of Lemma 2}

First, $b_{i} \geq \max \left\{v_{s}, v_{k k}, v_{k s}\right\}$ is a weakly dominated strategy. No owner wants to post a bid above its valuation of obtaining the assets and the assets will always be sold.

Inequality I1 $\left(v_{k k}>v_{k s}>v_{s}\right)$ : Since $v_{k s}>v_{s}$, a buy-to-keep owner will always have an incentive to outbid buy-to-sell owners. The buy-to-keep owners will then bid up the price to $v_{k k}$ to prevent a rival from obtaining the assets. A buy-to-keep owner will obtain the assets.

Inequality $\mathrm{I} 2\left(v_{k k}>v_{s}>v_{k s}\right)$ : Since $v_{s}>v_{k s}$, the outcome depends on what a buy-to-keep owner believes will happen if it does not win. If it believes that another buy-to-keep owner will win, buy-to-keep owners will then bid up the price to $v_{k k}$ and a buy-to-keep owner will obtain the assets. If it believes that a buy-to-sell owner will win, then since $v_{s}>v_{k s}$ the buy-to-sell owners will bid up the price to $v_{s}$ and a buy-to-keep owner will obtain the assets.

Inequality I3 $\left(v_{k s}>v_{k k}>v_{s}\right)$ : Since $v_{k s}>v_{s}$, a buy-to-keep owner will always have an incentive to outbid buy-to-sell owners. The buy-to-keep owners will then bid up the price to $v_{k k}$ to prevent a rival from obtaining the assets. A buy-to-keep owner will obtain the assets. Since buy-to-keep owners realize that a buy-to-sell owner will never obtain the assets $\left(v_{k s}>v_{s}\right)$, the price will not be bid up to $v_{k s}$.

Inequality I4 $\left(v_{k s}>v_{s}>v_{k k}\right)$ : Since $v_{k s}>v_{s}$, a buy-to-keep owner will always have an incentive to outbid buy-to-sell owners and bid up the price to slightly above $v_{s}$. However, only one buy-to-keep owner has this incentive, since no other buy-to-keep owner wants to outbid him or her $\left(v_{s}>v_{k k}\right)$. A buy-to-keep owner will then obtain the assets at price $v_{s}$.

Inequality I5 $\left(v_{s}>v_{k k}>v_{k s}\right)$ : Since $v_{s}>v_{k s}$, no buy-to-keep owners will want to outbid the buy-to-sell owners. The buy-to-sell owners will then bid up the price to $v_{s}$ and a buy-to-sell owner will obtain the assets.

Inequality I6 $\left(v_{s}>v_{k s}>v_{k k}\right)$ : Since $v_{s}>v_{k s}$, no buy-to-keep owners will want to outbid the buy-to-sell owners. The buy-to-sell owners will then bid up the price to $v_{s}$ and a buy-to-sell owner will obtain the assets. 


\section{A.3 Exogenous variable restructuring cost advantages}

Here we formally argue that if private equity firms buying to sell have a variable costs advantage, $0<f_{s}^{\prime}(r)<f_{k}^{\prime}(r)$ and $0<f_{s}^{\prime \prime}(r)<f_{k}^{\prime \prime}(r)$, then this advantage will lead to private equity firms providing more high powered incentive contracts $\hat{\mu}_{s}>\hat{\mu}_{k}$, which leads to more aggressive restructuring $r_{s}^{*}\left(\hat{\mu}_{s}\right)>r_{k}^{*}\left(\hat{\mu}_{k}\right)$. First, the compensation contract given to the manager is now

$$
w_{h}(b, \mu)=b+\mu\left[R_{A}(r)-F+\varepsilon-f_{h}(r)\right] \quad h=s, k
$$

and that the optimal restructuring intensity $r_{h}^{*}(\mu)$ depends on $h$ and become

$$
\mu \frac{d R_{A}}{d r}=C^{\prime}\left(r_{h}^{*}(\mu)\right)+f_{h}^{\prime}\left(r_{h}^{*}(\mu)\right) \quad h=s, k .
$$

Given the same contract $\mu$, a manager in a private equity backed firm with lower restructuring costs responds stronger to an increase in $\mu$ than a manager in an incumbent firm:

$$
\frac{d r_{s}^{*}}{d \mu}=-\frac{R_{A}^{\prime}}{\mu R_{A}^{\prime \prime}-C^{\prime \prime}-f_{s}^{\prime \prime}}>-\frac{R_{A}^{\prime}}{\mu R_{A}^{\prime \prime}-C^{\prime \prime}-f_{k}^{\prime \prime}}=\frac{d r_{k}^{*}}{d \mu}>0 .
$$

This holds since $f_{s}^{\prime \prime}<f_{k}^{\prime \prime}$. Next, we need to figure out the optimal share to give to the manager.

An incumbent will maximize expected profits $\mathrm{E}\left[R_{A}\left(r_{k}^{*}(\mu)\right)-F+\varepsilon-f_{k}\left(r_{k}^{*}(\mu)\right)-\widetilde{w}_{k}(b, \mu)\right]$ by optimally choosing the contract $\{b, \mu\}$. Assuming perfect competition between managers, the optimal contract must fulfill the participation constraint $w_{k}(b, \mu)-C\left(r_{k}^{*}(\mu)\right)-\Omega(\mu)=\bar{w}$, in which $\bar{w}$ is the outside option for the managers. Solving $\widetilde{w}_{k}(b, \mu)=\bar{w}+C\left(r_{k}^{*}(\mu)\right)+\Omega(\mu)$ from the participation constraint, and using $\mathrm{E}[\varepsilon]=0$, the expected profit can be written as

$$
\mathrm{E}\left[R_{A}\left(r_{k}^{*}(\mu)\right)-F+\varepsilon-f_{k}\left(r_{k}^{*}(\mu)\right)-w_{k}(b, \mu)\right]=R_{A}\left(r_{k}^{*}(\mu)\right)-\Gamma_{k}\left(r_{k}^{*}(\mu)\right)
$$

in which $\Gamma_{k}(\mu)=F+f_{k}\left(r_{k}^{*}(\mu)\right)+\bar{w}+C\left(r_{k}^{*}(\mu)\right)+\Omega(\mu)$ is the total costs for inducing restructuring, i.e. the sum of the expected restructuring costs and the compensation paid to the manager.

From equation (13), it now follows that the optimal share is $\mu_{k}^{*}=\arg \max _{\mu}\left[R_{A}\left(r_{k}^{*}(\mu)\right)-\right.$ $\left.\Gamma_{k}\left(r_{k}^{*}(\mu)\right)\right]$ with associated first-order condition

$$
\frac{d R_{A}}{d r} \frac{d r_{k}^{*}}{d \mu}=\Gamma_{k}^{\prime}\left(\hat{\mu}_{k}\right)
$$

The same arguments for a private equity firm gives that the optimal share to give to the manager is $\mu_{s}^{*}=\arg \max _{\mu}\left[R_{A}\left(r_{s}^{*}(\mu)\right)-R_{N A}\left(r_{s}^{*}(\mu)\right)-\Gamma_{s}\left(r_{s}^{*}(\mu)\right)\right]$ with associated first-order condition

$$
\left[\frac{d R_{A}}{d r}-\frac{d R_{N A}}{d r}\right] \frac{d r_{s}^{*}}{d \mu}=\Gamma_{s}^{\prime}\left(\hat{\mu}_{s}\right)
$$


Making use of the total cost $\Gamma_{h}(\mu)=F+f_{h}\left(r_{h}^{*}(\mu)\right)+\bar{w}+C\left(r_{h}^{*}(\mu)\right)+\Omega(\mu)$, we can rewrite the first-order condition for the manager in (46) as:

$$
\frac{d R_{A}}{d r}-f_{h}^{\prime}\left(r_{h}^{*}(\mu)\right)-C^{\prime}\left(r_{h}^{*}(\mu)\right)=(1-\mu) \frac{d R_{A}}{d r} \quad h=s, k .
$$

Since $\Gamma_{h}(\mu)=F+f_{h}\left(r_{h}^{*}(\mu)\right)+\bar{w}+C\left(r_{h}^{*}(\mu)\right)+\Omega(\mu)$, we also have:

$$
\frac{\left.d \Gamma_{h}(\mu)\right)}{d \mu}=f_{h}^{\prime}\left(r_{h}^{*}(\mu)\right) \frac{d r_{h}^{*}}{d \mu}+C^{\prime}\left(r_{h}^{*}(\mu)\right) \frac{d r_{h}^{*}}{d \mu}+\Omega^{\prime}(\mu) \quad h=s, k .
$$

Using equation (51) and (52), We can first rewrite equation (49) as follows:

$$
\begin{aligned}
\frac{d R_{A}}{d r} \frac{d r_{k}^{*}}{d \mu} & =f_{k}^{\prime}\left(r_{k}^{*}(\mu)\right) \frac{d r_{k}^{*}}{d \mu}+C^{\prime}\left(r_{k}^{*}(\mu)\right) \frac{d r_{k}^{*}}{d \mu}+\Omega^{\prime}(\mu) \\
{\left[\frac{d R_{A}}{d r}-f_{k}^{\prime}\left(r_{k}^{*}(\mu)\right)-C^{\prime}\left(r_{k}^{*}(\mu)\right)\right] \frac{d r_{k}^{*}}{d \mu} } & =\Omega^{\prime}(\mu) \\
\left(1-\mu_{k}^{*}\right) \frac{d R_{A}}{d r} \frac{d r_{k}^{*}}{d \mu} & =\Omega^{\prime}\left(\mu_{k}^{*}\right)
\end{aligned}
$$

Similarly, using equation (52) we also can rewrite equation (50) as follows :

$$
\begin{aligned}
& {\left[\frac{d R_{A}}{d r}-\frac{d R_{N A}}{d r}\right] \frac{d r_{s}^{*}}{d \mu} }=f_{s}^{\prime}\left(r_{s}^{*}(\mu)\right) \frac{d r_{s}^{*}}{d \mu}+C^{\prime}\left(r_{s}^{*}(\mu)\right) \frac{d r_{s}^{*}}{d \mu}+\Omega^{\prime}(\mu) \\
& {\left[\frac{d R_{A}}{d r}-f_{s}^{\prime}\left(r_{s}^{*}(\mu)\right)-C^{\prime}\left(r_{s}^{*}(\mu)\right)\right] \frac{d r_{s}^{*}}{d \mu}-\frac{d R_{N A}}{d r} \frac{d r_{s}^{*}}{d \mu}=\Omega^{\prime}(\mu) } \\
&\left(1-\mu_{s}^{*}\right)\left[\frac{d R_{A}}{d r}-\frac{d R_{N A}}{d r}\right] \frac{d r_{s}^{*}}{d \mu}=\Omega^{\prime}\left(\mu_{s}^{*}\right)
\end{aligned}
$$

Hence, the manager's first-order condition in equation (47), (49) and (50) can be re-written as:

$$
\left(1-\hat{\mu}_{k}\right) \frac{d R_{A}}{d r} \frac{d r_{k}^{*}}{d \mu}=\Omega^{\prime}\left(\hat{\mu}_{k}\right), \quad\left(1-\hat{\mu}_{s}\right)\left[\frac{d R_{A}}{d r}-\frac{d R_{N A}}{d r}\right] \frac{d r_{s}^{*}}{d \mu}=\Omega^{\prime}\left(\hat{\mu}_{s}\right)
$$

Noting that $\frac{d R_{N A}}{d r}<0$ and $\frac{d r_{s}^{*}}{d \mu}>\frac{d r_{k}^{*}}{d \mu}>0$ from equation(47), equation (59) reveals that private equity firms give stronger incentive contracts to their managers, $\hat{\mu}_{s}>\hat{\mu}_{k}$. From equation (47), private equity firms must then induce more restructuring $\left(r_{s}^{*}\left(\hat{\mu}_{s}\right)>r_{k}^{*}\left(\hat{\mu}_{k}\right)\right)$.

\section{References}

[1] Acharya, Viral V., and Conor Kehoe, 2008, Corporate governance and value creation: Evidence from private equity, Working Paper, London Business School.

[2] Amess, Kevin, 2002, Management buyouts and firm-level productivity: evidence from a panel of U.K. Manufacturing Firms, Scottish Journal of Political Economy 49, 304-317. 
[3] Amess, Kevin, 2003, The effects of management buyouts and on firm-level technical efficiency: evidence from a panel of U.K. machinery and equipment manufacturers, Journal of Industrial Economics 51, 35-44.

[4] Axelson, Ulf, Tim Jenkinson, Per Strömberg and Michael S. Weisbach, 2009, Leverage and pricing in buyouts: An empirical analysis, Working Paper.

[5] Badertscher, B., Katz, S. and Rego, S. O., (2009). "The Impact of Private Equity Ownership on Corporate Tax Avoidance," HBS Working Paper 10-004.

[6] Berle, Adolph, and Gardiner Means. 1932. The Modern Corporation and Private Propert. New York: The Commerce Clearing House.

[7] Bolton, Patrick, and David Scharfstein, 1990, A theory of predation based on agency problems in financial contracting, American Economic Review 80, 93-106.

[8] Boone, Audra, and Harold Mulherin, 2007. How are firms sold? Journal of Finance 62: 847-875.

[9] Brau, James C., Bill Francis, and Ninon Kohers, 2003, The choice of IPO versus takeover: Empirical evidence, Journal of Business 76, 583-612.

[10] Brander, James A., and Tracy R. Lewis, 1986, Oligopoly and financial structure: The limited liability effect, American Economic Review 76, 956-970.

[11] Brander, James A., and Tracy R. Lewis, 1988, Bankruptcy costs and the theory of oligopoly, Canadian Journal of Economics 21, 221-243.

[12] Chemmanur, Thomas J. and Bayar, Onur, 2009. Product Market Competition, IPOs versus Acquisitions, and the Valuation Premium Puzzle: A Theoretical Analysis. Available at SSRN: http://ssrn.com/abstract=966004

[13] Chevalier, Judith A., 1995a, Capital structure and product-market competition: Empirical evidence from the supermarket industry, American Economic Review 85, 415-435.

[14] Chevalier, Judith A., 1995b, Do LBO supermarkets charge more? An empirical analysis of the effects of LBOs on supermarket pricing, Journal of Finance 50, 1095-1112.

[15] Coase, Ronald, 1960, The problem of social cost. Journal of Law and Economics 3: 1-44.

[16] Davis, Steven, John Haltiwanger, Ron Jarmin, Josh Lerner, and Javier Miranda. 2009. Private equity, jobs and productivity. In The Globalization of Alternative Investments Working Papers Volume 2: The Global Economic Impact of Private Equity Report 2009, ed. Anduradha Gurung and Josh Lerner, 25-43. Geneva: World Economic Forum. 
[17] Deneckere, Raymond, and Carl Davidson, 1985, Incentives to form coalitions with Bertrand competition, RAND Journal of Economics 16, 473-486.

[18] Farrell, Joseph, and Carl Shapiro, 1990, Asset ownership and market structure in oligopoly, RAND Journal of Economics 21, 275-292.

[19] Fridolfsson, Sven-Olof and Johan Stennek, 2005, Why Mergers Reduce Profits And Raise Share Prices-A Theory Of Preemptive Mergers, Journal of the European Economic Association, MIT Press, vol. 3(5), pages 1083-1104, 09.

[20] Gans, Joshua S., 2005, Markets for Ownership, RAND Journal of Economics 36: 433455.

[21] Gilbert, Richard J. and Newbery, David M, 1992, Alternative Entry Paths: The Build or Buy Decision, Journal of Economics \& Management Strategy 1:129-50.

[22] Gowrisankaran, Gautam, 1999, A dynamic model of endogenous horizontal mergers, RAND Journal of Economics 30, $56-83$.

[23] Grossman, Sanford J. and Oliver D. Hart, 1986, The Costs and Benefits of Ownership: A Theory of Vertical and Lateral Integration,

Journal of Political Economy 94, pp 691

[24] Hart, Oliver D., and John Moore, 1990, Property rights and the nature of the firm, Journal of Political Economy 98, 1119-1158.

[25] Harris, Richard I., Donald S. Siegel, and Mike Wright, 2005, Assessing the impact of management buyouts on economic efficiency: plant level evidence from the United Kingdom, The Review of Economics and Statistics 87, 148-153.

[26] Horn, Henrik, and Lars Persson, 2001, The equilibrium ownership of an international oligopoly, Journal of International Economics 53, 307-333.

[27] Jehiel, Philippe and Benny Moldovanu,1999, Resale Markets and the Assignment of Property Rights. The Review of Economic Studies 66, 971-991

[28] Jehiel, Philippe, and Benny Moldovanu, 2000, Auctions with Downstream Interaction among Buyers, RAND Journal of Economics 31, 768-91.

[29] Jehiel, Philippe, Benny Moldovanu and Ennio Stacchetti, 1999, Multidimensional mechanism design for auctions with externalities, Journal of Economic Theory 85, 258-293.

[30] Jensen, Michael C., 1986, Agency Costs of Free Cash Flow, Corporate Finance, and Takeovers, The American Economic Review 76, pp. 323-329. 
[31] Jensen, Michael C., 1989, Eclipse of the public corporation, Harvard Business Review Sept-Oct, 61-74.

[32] Jensen, Michael C., and William H. Meckling, 1976, Theory of the firm: managerial behavior, agency costs and ownership structure, Journal of Financial Economics 3, 305360 .

[33] Jensen, Michael C., and Kevin J. Murphy, 1990, Performance pay and top management incentives, Journal of Political Economy 98, 225-264.

[34] Kaplan, Steven N., 1989a, The Effects of management buyouts on operating performance and value, Journal of Financial Economics 24, 217-254.

[35] Kaplan, Steven N., 1989b, Management Buyouts: Evidence on Taxes as a Source of Value, The Journal of Finance, Vol. 44, No. 3,611-632.

[36] Kaplan, Steven N., and Per Strömberg, 2009, Leveraged buyouts and private equity, Journal of Economic Perspectives 23, Winter.

[37] Katz, M. L. and Shapiro C, 1996, "How to licence intangible property”, Quarterly Journal of Economics 101: pp 567-590

[38] Kamien, Morton I., and Israel Zang, 1990, The Limits of Monopolization through Acquisition, Quarterly Journal of Economics 105: 465-99.

[39] Kovenock Daniel, and Gordon Phillips, 1995, Capital Structure and Product Market Rivalry: How do We Reconcile the Theory and the Evidence, American Economic Review, 85, 403-408.

[40] Lerner, Josh, 1994, Venture capitalists and the decision to go public, Journal of Financial Economics, 35, 293-316.

[41] Leslie, Phillip, and Paul Oyer, 2008, Managerial incentives and value creation: Evidence from private equity, NBER Working Paper No. W14331.

[42] Lichtenberg, Frank R., Donald S. Siegel, 1990, The effect of leveraged buyouts on productivity and related aspects of firm behavior, Journal of Financial Economics 27, 165-194.

[43] Maksimovic, Vojislav, 1988, Capital structure in repeated oligopolies, Rand Journal of Economics 19, 389-407.

[44] Miao, Jianjun, 2005, Optimal capital structure and industry dynamics, Journal of Finance 60, 2621-2659.

[45] Muscarella, Chris J., and Michael R. Vetsuypens, 1990, Efficiency and organizational structure: A study of reverse LBOs, Journal of Finance 45, 1389-1414. 
[46] Norbäck, Pehr-Johan, and Lars Persson, 2009, The organization of the innovation industry: Entrepreneurs, venture capitalists, and oligopolists, Journal of the European Economic Association, forthcoming.

[47] Perry, Martin K., and Robert H. Porter, 1985, Oligopoly and the incentive for horizontal merger, American Economic Review 75, 219-227.

[48] Phillips, Gordon M., 1995, Increased debt and industry product markets. An empirical analysis, Journal of Financial Economics 37, 189-238.

[49] Poulsen, A., and M. Stegemoller, 2008, Moving firms from private to public ownership: Selling out to public firms vs. initial public offerings, Financial Management 37, 81-101.

[50] Salant, Stephen W., Sheldon Switzer, and Robert J. Reynolds, 1983, Losses from horizontal merger: The effects of an exogeneous change in industry structure on Cournot-Nash equilibrium, Quarterly Journal of Economics 98, 185-199.

[51] Williams, Joseph T., 1995, Financial and industrial structure with agency, Review of Financial Studies 8, 431-474. 